\title{
Aryl(hydro)boranes: versatile building blocks for boron-doped $\pi$-electron materials
}

\author{
Andreas Lorbach, Alexander Hübner and Matthias Wagner*
}

Boron-containing $\pi$-conjugated molecules offer a substantial application potential in the field of organic electronics. During the last decade, aryl(hydro)boranes have established themselves as versatile novel building blocks for sophisticated boron-doped materials. This perspective article comprehensively discusses key structural motifs and reactivity patterns of recently developed aryl(hydro)boranes and shows how these have been used for the synthesis of macromolecular organoboranes through hydroboration polymerisation, ring-opening polymerisation and condensation polymerisation protocols.

\section{Introduction}

Carbon-based $\pi$-conjugated materials can be designed such that they possess (i) useful charge-transport properties, (ii) a high light absorption coefficient or (iii) pronounced photo-/electroluminescence. These fundamental features qualify such organic compounds for applications in electrical technology, ${ }^{1,2}$ formerly the domain of metals and metalloids such as silicon. Compared to energy- and cost-intensive silicon devices, lightweight, mechanically flexible, printable and highly tunable organic materials offer favourable options for the fabrication of electronic circuits and logic elements, ${ }^{3-5}$ advanced solar cells, ${ }^{5,6}$ and large-area displays. ${ }^{7}$

Institut für Anorganische Chemie, J.W. Goethe-Universität Frankfurt, Max-von-Laue-Strasse 7, D-60438 Frankfurt (Main), Germany. E-mail: Matthias.Wagner@chemie.uni-frankfurt.de

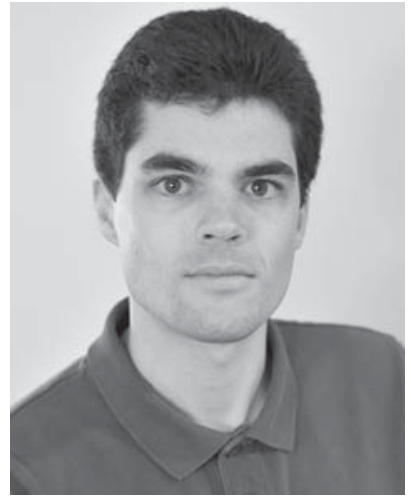

Dr Andreas Lorbach
Dr Andreas Lorbach, born in 1982, studied chemistry at the J.W. Goethe-Universität Frankfurt/Main and joined M. Wagner's research group in 2007. He focused on the investigation of novel 9,10-dihydro9,10-diboraanthracene derivatives and finished his Ph.D. thesis in 2011. Dr Lorbach is presently doing postdoc research as a Feodor Lynen Fellow of the Alexander von Humboldt Foundation in the group of G. C. Bazan (University of California, Santa Barbara). His current research interests include fullerene chemistry in general and the development of novel devices for optoelectronic applications in particular.

During the last decade, it became apparent that the qualities of organic materials can be improved further if selected carbon atoms are replaced by boron atoms. ${ }^{8}$ When a tricoordinate boron centre interacts with an adjacent $\pi$-electron system, the vacant $\mathrm{p}_{z}$ orbital exerts a strong $\pi$-acceptor effect and thereby extends the $\pi$-conjugation pathway ( $c f$. Fig. 1). This overlap is particularly pronounced in the ground state LUMO, but much less so in the HOMO. ${ }^{9}$ The resulting decrease in the LUMO energy (i) affects the HOMO-LUMO gap and thereby the absorption and emission characteristics of the compound, and (ii) renders the borondoped $\pi$ system a better electron acceptor. Upon going from monomeric to oligomeric species, the HOMO-LUMO separation gradually becomes smaller. This trend levels off when the effective conjugation length of the material is reached. As a representative example, quantum-chemical calculations on an oligo( $p$-phenylenevinyleneborane) revealed an effective conjugation length in the range of $4-5$ repeating units. ${ }^{10}$ Because of

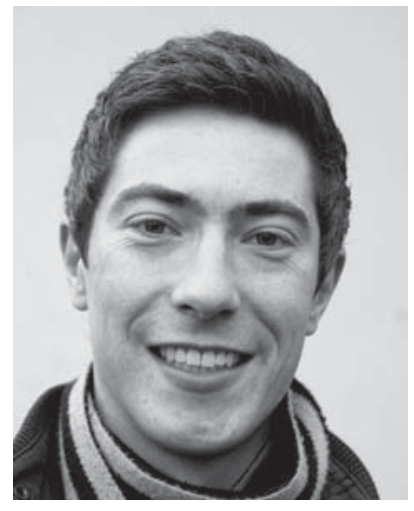

Alexander Hübner, M.Sc.
Alexander Hübner, born in 1985, obtained his B.Sc. and M.Sc. degrees from the J.W. Goethe-Universität Frankfurt/ Main. He is currently working on his Ph.D. thesis in the group of $M$. Wagner and investigating the ring-opening oligomerisation of 9-borafluorene. 

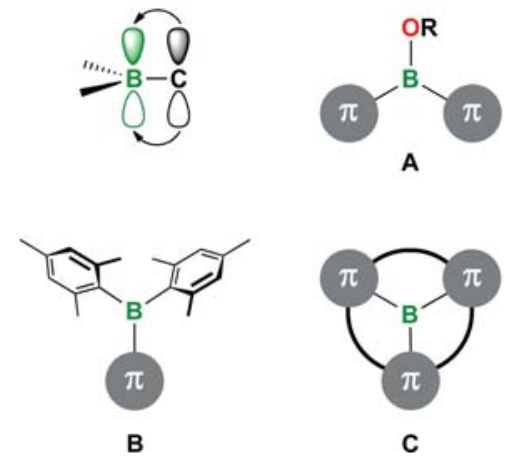

Fig. 1 Schematic sketch of the electronic interaction between the vacant $\mathrm{p}_{z}$ orbital of a tricoordinate boron atom and an adjacent $\pi$ system. Three different modes of protecting organoboranes from hydrolytic degradation: Thermodynamic stabilisation by $\pi$-donor substituents (A), kinetic stabilisation by bulky mesityl groups (B), kinetic and thermodynamic stabilisation by a rigid, planar-constrained framework $(\mathbf{C})$.

the inherently electron-deficient nature of tricoordinate boron, the incorporation of this heteroatom into a $\pi$-conjugated polymer backbone leads to materials with n-type electronic properties. $^{11,12} \mathrm{n}$-Type semiconducting polymers are rare but in great demand: thin-film organic electronic devices like organic photovoltaic cells (OPVCs) and organic light-emitting diodes (OLEDs) contain at least two semiconducting materials ( $p$ - and n-type) with offsets in their HOMO-LUMO levels. The interface between the p-type and the n-type layer has to be designed such that either charge separation (OPVCs) or emissive charge recombination (OLEDs) is the favoured process. A fine-tuning of the device properties therefore requires the possibility to select from a broad variety of p- and n-type materials. ${ }^{13,14}$ Given this background, $\pi$-conjugated organoboron structures are currently enjoying increasing interest and a first generation of main-chain boron-doped polymers has already been commercialised. ${ }^{12}$

Certain boron-doped $\pi$-electron systems also stand out for their useful photophysical properties, such as photoluminescence, electroluminescence and nonlinear optical behaviour. ${ }^{8}$ An exciting recent discovery are photoswitchable tetracoordinate

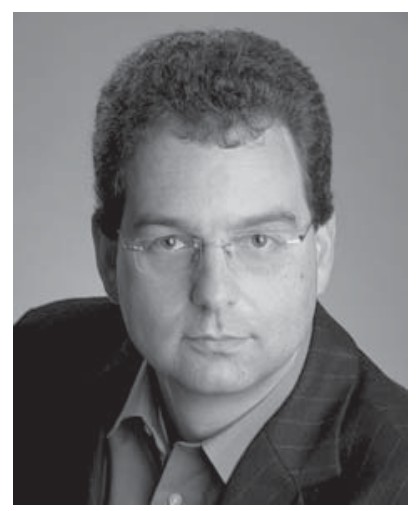

Prof. Dr Matthias Wagner
Prof. Dr Matthias Wagner obtained his Ph.D. with H. Nöth at the Ludwig-Maximilians-Universität München. He stayed for a postdoc with M. L. H. Green, FRS, at Oxford University and finished his Habilitation in 1997 at the Technische Universität München in the group of W. A. Herrmann. Since 1999, he holds the chair of Organometallic Chemistry at the J.W. Goethe-Universität Frankfurt/ Main. His current research interests are general boron chemistry, the investigation of reactive intermediates and organometallic catalysis directed towards materials synthesis. arylboron compounds in which a thermally reversible $\mathrm{B}-\mathrm{C} / \mathrm{C}-\mathrm{C}$ bond rearrangement leads to colour changes and fluorescence quenching upon irradiation with $350-450$ nm light. ${ }^{15}$

Since triorganoboranes are strong Lewis acids, they have a distinct propensity to form adducts with Lewis bases. The concomitant interruption of the $\pi$-conjugation pathway changes the optoelectronic characteristics of the borane, thereby signalling the presence of the Lewis base, which can be exploited for sensory applications. ${ }^{16}$ Reversible adduct formation has also been utilised to activate Lewis bases during Lewis acid-mediated catalytic transformations. Aryl- as well as perfluoroarylboranes are receiving particular attention in this respect. ${ }^{17}$

Despite the numerous exciting perspectives currently emerging in the literature, research on boron-containing $\pi$-conjugated materials is still at a comparatively early stage. The development of the field is slowed down due to the air- and moisture-sensitivity of most organoboron compounds as well as their limited synthetic accessibility.

Any thermodynamic stabilisation of the materials through the introduction of strong $\pi$-donor substituents (e.g., OR) will necessarily perturb the $\pi$ conjugation between the boron atom and its remaining organyl substituents. The formation of crossconjugated systems is consequently not a preferred option in the present context ( $c f$. A; Fig. 1). Alternatively, the boron centre can be kinetically shielded from $\mathrm{H}_{2} \mathrm{O}$ and/or $\mathrm{O}_{2}$ attack. A large proportion of organoboranes employed in materials science and sensor technology therefore contain one bulky substituent, in many cases even two ( $c f$. the highly popular $\mathrm{BMes}_{2}$ group; Mes $=2,4,6$-trimethylphenyl; mesityl). ${ }^{18}$ However, the concept of steric protection also has its limitations, because steric congestion in compounds B (Fig. 1) leads to twisting of the mesityl substituents about the $\mathrm{B}-\mathrm{C}$ bonds and thereby to decreased $\pi$ conjugation across the boron centre. Thus, attachment of a $\mathrm{BMes}_{2}$ group merely adds one vacant boron-centred $\mathrm{p}_{z}$ orbital to the $\pi$-electron cloud, while the two mesityl rings remain more or less spectator groups. A third strategy to achieve improved inertness towards air and moisture is the synthesis of planar-constrained frameworks, as illustrated by the triorganylborane $\mathbf{C}$ (Fig. 1). In this case, the benefit from the constrained geometry is twofold: (i) Boron tetracoordination usually precedes hydrolytic/oxidative decay. The required pyramidalisation of the boron centre is prevented by the rigid molecular architecture, rendering the introductory degradation step energetically unfavourable. (ii) Since a rotation about the $\mathrm{B}-\mathrm{C}$ bonds is not possible, an optimal $\pi$ conjugation within the entire molecule $\mathbf{C}$ will be guaranteed at all times.

For an introduction of boryl substituents into $\pi$-electron systems, the following synthesis protocols have been developed:

(1) A classic approach uses nucleophilic substitution reactions between organometallic reagents (e.g., $\left(\mathrm{R}^{\pi}\right) \mathrm{Li},\left(\mathrm{R}^{\pi}\right) \mathrm{MgBr}$; $\mathrm{R}^{\pi}=$ $\pi$-conjugated organyl substituent) and boranes bearing suitable leaving groups (e.g., $\left.\mathrm{R}_{2} \mathrm{BX} ; \mathrm{X}=\mathrm{Cl}, \mathrm{Br}\right) .{ }^{19-21} \mathrm{In}$ order to achieve a higher chemoselectivity and to avoid the formation of unwanted "ate"-complexes $\left[\mathrm{R}_{2} \mathrm{~B}\left(\mathrm{R}^{\pi}\right)_{2}\right]^{-}$, less reactive organometallics (e.g., $\left(\mathrm{R}^{\pi}\right) \mathrm{Cu},{ }^{22}\left(\mathrm{R}^{\pi}\right) \mathrm{HgCl}$ or $\left.\left(\mathrm{R}^{\pi}\right)_{2} \mathrm{Hg}^{23}\right)$ or poorer leaving groups $(\text { e.g., } \mathrm{X}=\mathrm{OR})^{19,20}$ have been employed. A related strategy relies on $\mathrm{Si} / \mathrm{B}$ or $\mathrm{Sn} / \mathrm{B}$ exchange reactions. ${ }^{24}$

For certain organometallic compounds (e.g., $\left(\mathrm{C}_{5} \mathrm{H}_{5}\right) \mathrm{Mn}(\mathrm{CO})_{3}$; $\left.\left(\mathrm{C}_{5} \mathrm{H}_{5}\right)_{2} \mathrm{M}, \mathrm{M}=\mathrm{Fe}, \mathrm{Ru}, \mathrm{Os}\right)$, a direct, uncatalysed borylation 


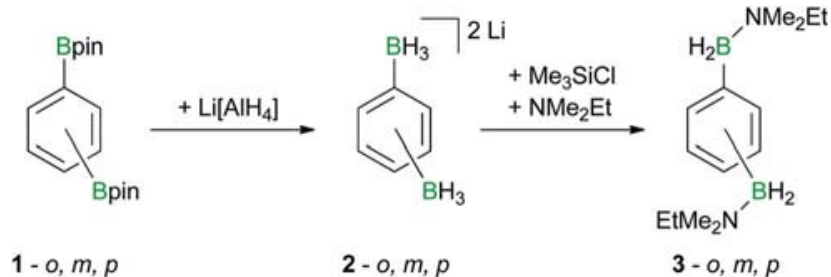

Scheme 1 Diborylated benzenes 1 obtained through transition-metal mediated borylation reactions and their conversion into stable and isolable lithium aryl(trihydro)borates $\mathbf{2}$ or aryl(hydro)borane adducts $\mathbf{3}$.

with $\mathrm{BBr}_{3}$ is possible. ${ }^{25}$ For example, depending on the stoichiometry, mono-, 1,1'-bis- or 1,1',3,3'-tetrakis(dibromoboryl)ferrocene can be prepared with high selectivity and in excellent yield.

(2) A very elegant recent strategy is the transition metal-catalysed borylation of $\mathrm{Ar}-\mathrm{X}(\mathrm{Ar}=\operatorname{aryl} ; \mathrm{X}=\mathrm{Cl}, \mathrm{Br}, \mathrm{I})^{26}$ or $\mathrm{Ar}-\mathrm{H}^{27}$ using pinacol borane reagents like HBpin or pinB-Bpin $\left(\mathrm{H}_{2}\right.$ pin $=$ 2,3-dimethylbutane-2,3-diol). The Ar-Bpin species thus obtained are valuable starting materials for further $\mathrm{C}-\mathrm{C}$ coupling reactions via Suzuki-Miyaura protocols (which proceed with loss of the boryl group) ${ }^{28} \mathrm{Ar}-\mathrm{Bpin}$ compounds themselves are less useful in the context under consideration here, because the $\pi$-acceptor character of the boron atoms is largely tamed by its bidentate alkoxy substituent. However, it has recently been shown that benzene derivatives bearing one, two or even three Bpin substituents (e.g., 1; Scheme 1) can be transformed into the corresponding trihydroborates (e.g., 2) upon treatment with Li$\left[\mathrm{AlH}_{4}\right] .{ }^{29-31}$ Subsequent hydride abstraction leads to transient aryl(dihydro)boranes, ${ }^{29}$ which are promising building blocks for the synthesis of boron-doped $\pi$ systems through the in situ hydroboration of alkynes (see below); the intermediate boranes have also been trapped as their Lewis base adducts (e.g., 3; Scheme 1).

We note in passing that the catalytic diboration of alkynes $\mathrm{RC} \equiv \mathrm{CR}$ with, e.g., pinB-Bpin also offers a route to boron-containing conjugated molecules. ${ }^{32}$ However, further transformation of the primary products $\operatorname{pinBC}(\mathrm{R})=\mathrm{C}(\mathrm{R}) \mathrm{Bpin}$ into vinyl(dihydro)boranes, like in the case of the Ar-Bpin species (Scheme 1), will be problematic due to self-hydroboration.

(3) A third approach exploits the hydroboration of alkynes $\mathrm{HC} \equiv \mathrm{CR}^{\pi}$ with organyl(hydro)boranes $\left(\mathrm{R}^{\pi}\right)_{n} \mathrm{BH}_{3-n}(n=1,2)$. As alluded to above, the choice of $\mathrm{R}^{\pi}$ substituents has to be restricted to (hetero)aryl moieties in order to avoid side reactions between two borane molecules. Even though hydroboration reactions between alkyl(hydro)boranes (e.g., 9-borabicyclo[3.3.1]nonane, $(9-\mathrm{BBN})_{2}$; thexylborane, $\left(\mathrm{TexBH}_{2}\right)_{2}$, Tex $=\mathrm{C}\left(\mathrm{CH}_{3}\right)_{2}-$ $\left.\mathrm{C}(\mathrm{H})\left(\mathrm{CH}_{3}\right)_{2}\right)$ and olefins or alkynes have been well established in preparative chemistry for decades, ${ }^{33}$ much less is known about the properties and the reactivity of aryl(hydro)boranes. Among the few thoroughly characterised examples are the mesityl(hydro)boranes $\left(\mathrm{MesBH}_{2}\right)_{2}{ }^{34}$ and $\left(\mathrm{Mes}_{2} \mathrm{BH}\right)_{2}{ }^{35-37}$ the tripyl(hydro)boranes $\left(\text { TripBH }{ }_{2}\right)_{2}{ }^{38,39}$ and $\operatorname{Trip}_{2} \mathrm{BH}^{37,40}$ (Trip $=2,4,6$ $i \mathrm{Pr}_{3} \mathrm{C}_{6} \mathrm{H}_{2}$; tripyl) as well as bis(pentafluorophenyl)(hydro)borane $\left(\left(\mathrm{C}_{6} \mathrm{~F}_{5}\right)_{2} \mathrm{BH}\right)_{2} \cdot{ }^{41-43}$ The mesityl- and tripyl(hydro)boranes have been developed mainly in the quest for isolable and storable alternatives to the far less stable $\left(\mathrm{TexBH}_{2}\right)_{2}$, one of the most important and widely used hydroborating agents. ${ }^{44}$ The monomeric $^{37}$ compound $\operatorname{Trip}_{2} \mathrm{BH}$ hydroborates alkynes only slowly and with surprisingly little regioselectivity; at room temperature, it does not hydroborate alkenes at all. ${ }^{40}$ Despite its smaller bulk compared to Trip ${ }_{2} \mathrm{BH},\left(\mathrm{Mes}_{2} \mathrm{BH}\right)_{2}$ is among the most regioselective reagents for the hydroboration of unsymmetrical alkynes. Moreover, any alkyne can be hydroborated in the presence of any type of alkene, because the rates of reactions with alkynes and alkenes differ substantially. ${ }^{36}$ Even though $\left(\left(\mathrm{C}_{6} \mathrm{~F}_{5}\right)_{2} \mathrm{BH}\right)_{2}$ is yet less sterically demanding than $\left(\mathrm{Mes}_{2} \mathrm{BH}\right)_{2}$, hydroboration reactions with $\left(\left(\mathrm{C}_{6} \mathrm{~F}_{5}\right)_{2} \mathrm{BH}\right)_{2}$ generally occur with comparable or better regio- and chemoselectivity than with most other reagents. Again, 1-alkynes can selectively be monohydroborated to the corresponding vinylboranes $\left(\mathrm{C}_{6} \mathrm{~F}_{5}\right)_{2} \mathrm{BC}(\mathrm{H})=\mathrm{C}(\mathrm{H}) \mathrm{R}$; the conversion rates are high. ${ }^{41,42}$

With regard to the synthesis of extended boron-doped $\pi$-conjugated materials, hydroboration protocols are particularly attractive, because they are based on an atom-economical ${ }^{45}$ addition reaction yielding exclusively the target molecules without simultaneous formation of potentially contaminating byproducts (e.g., $\mathrm{LiX}, \mathrm{MgX}_{2}, \mathrm{Me}_{3} \mathrm{SnX}$ ). Various sorts of (aryl)alkynes make suitable substrates, provided that it is feasible to stop the reaction after the first hydroboration event at the (aryl)alkenylborane stage. As mentioned above, $\operatorname{Trip}_{2} \mathrm{BH}, \quad\left(\operatorname{Mes}_{2} \mathrm{BH}\right)_{2}$ and $\left(\left(\mathrm{C}_{6} \mathrm{~F}_{5}\right)_{2} \mathrm{BH}\right)_{2}$ all fulfil this prerequisite. However, to exploit the full potential of the hydroboration approach in the future, a much larger variety of readily available aryl(hydro)boranes will be required, and their design has to take care of the problem of substituent redistribution: in contrast to numerous mixed triorganoboranes $B\left(R^{1}\right)\left(R^{2}\right)\left(R^{3}\right)$, which exist as stable molecules even at moderately elevated temperatures, organo(hydro)boranes $\mathrm{R}_{n} \mathrm{BH}_{3-n}(n=1,2)$ tend to form exchange equilibria in which all four conceivable species $(n=0-3)$ are present. ${ }^{46-48}$ In fact, trace amounts of hydroboranes efficiently catalyse substituent redistribution reactions between triorganoboranes. ${ }^{46-48}$ In the cases of the tripyl- and mesityl(hydro)boranes, unwanted dismutation reactions are suppressed by the bulky Trip and Mes substituents. But even though steric bulk is also beneficial to the regioselectivity of the reagents, it has distinct disadvantages once the focus is placed on the preparation of maximally extended $\pi$-delocalised species ( $c f$. the above discussion of compounds B; Fig. 1). Novel, more sophisticated aryl(hydro)boranes for applications in organic electronics therefore contain cyclic structures ( $c f$. C; Fig. 1), which (i) can be expected to suffer less from uncontrolled dismutation processes than their open-chain congeners, (ii) promote $\pi$ conjugation by reducing the rotational degrees of freedom within the molecule, (iii) show enhanced stability towards hydrolysis, because cyclic $\pi$ systems are usually rather rigid.

The purpose of this feature article is to provide a critical survey of the newest generation of aryl(hydro)borane building blocks for the synthesis of boron-containing $\pi$-conjugated materials. Emphasis will be put on the hydroboration approach, but also on most recent findings regarding synthetically useful substituent scrambling reactions of aryl(hydro)boranes.

\section{The new generation of aryl(hydro)boranes}

The easiest means to convert the simplest diarylboranes, i.e. the diphenylboranes, into cyclic structures, is the replacement of two ortho-hydrogen atoms by a $\mathrm{C}-\mathrm{C}$ bond to obtain 9-borafluorenes 


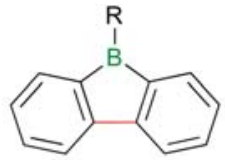

D

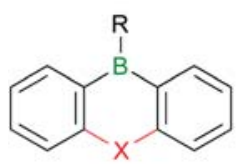

E

PR', O, S, Se
$X=\mathrm{BR}, \mathrm{CH}_{2}, \mathrm{NR}$,

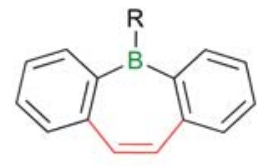

$\mathbf{F}$

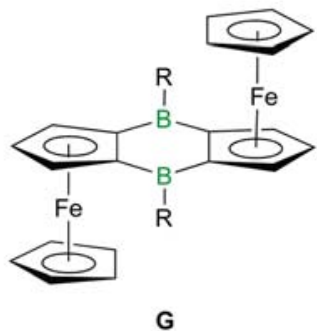

Fig. 2 The cyclic diphenylboranes 9-borafluorene (D), 9-boraanthracene $(\mathbf{E})$, dibenzo $\left[b_{2} f\right]$ borepin $(\mathbf{F})$ and a ferrocene analogue of 9,10 dihydro-9,10-diboraanthracene (G).

(D; Fig. 2). Other options are to link the two phenyl rings by a one-atom bridge or by a vinylene linker, thereby generating 9-boraanthracenes $(\mathbf{E})$ or dibenzo $[b, f]$ borepins $(\mathbf{F})$, respectively (Fig. 2). Moreover, certain organometallic moieties (e.g., ferrocene, $\left(\mathrm{C}_{5} \mathrm{H}_{5}\right)_{2} \mathrm{Fe}$; cymantrene, $\left.\left(\mathrm{C}_{5} \mathrm{H}_{5}\right) \mathrm{Mn}(\mathrm{CO})_{3}\right)$ can be employed in place of aryl rings as exemplified by Jäkle's compounds $\mathbf{G}$ (Fig. 2), the ferrocene analogues of 9,10-dihydro9,10-diboraanthracenes $(\mathbf{E} ; \mathrm{X}=\mathrm{BR}){ }^{49}$

The central borole ring of $\mathbf{D}$ differs from the borepin ring of $\mathbf{F}$ not only in the number of edges, but, more fundamentally, in its electronic structure: boroles are Hückel antiaromatics ${ }^{50}$ whereas borepins are aromatic species. ${ }^{51}$ The character of 9-boraanthracenes $(\mathbf{E})$ depends on whether the fragment $\mathrm{X}$ carries an electron lone pair (X = NR', PR', O, S, Se; formal Hückel $6 \mathrm{e}^{-}$aromatic molecules $)^{52}$ or a vacant $\mathrm{p}_{z}$ orbital $\left(\mathrm{X}=\mathrm{BR}\right.$; formal Hückel $4 \mathrm{e}^{-}$ antiaromatic molecule).

Numerous derivatives of $\mathbf{D},{ }^{53} \mathbf{E}^{54}$ and $\mathbf{F}^{55}$ are known, the vast majority of which possess bulky substituents on the boron centres. Until recently, however, only little was known about the structures and properties of the parent aryl(hydro)borane structures. Of all three candidates $\mathbf{D}-\mathbf{F}$, the resonance-stabilised dibenzo $[b, f]$ borepin $(\mathbf{F} ; \mathrm{R}=\mathrm{H})$ should be the one that suffers least from a lack of steric protection. Indeed, van Tamelen et al. have claimed the synthesis of $\mathbf{F}(\mathrm{R}=\mathrm{H})$ already in $1960,{ }^{56}$ albeit in the form of its pyridine adduct. The structure proposal was mainly based upon the acid-promoted hydrolytic transformation of the synthesis product to the boronic acid $\mathbf{F}(\mathrm{R}=\mathrm{OH})$. Köster et al. have described the synthesis of parent, free borafluorene $\mathbf{D}$ $(\mathrm{R}=\mathrm{H})$ from 9-chloro-9-borafluorene and $\mathrm{Na}\left[\mathrm{HBEt}_{3}\right] .{ }^{57}$ Very few analytical data were provided, and, in the light of more recent results (see below), the described insolubility of the compound as well as its apparent thermostability suggest that the published results need to be refined. In a publication of 1973 , van Veen and Bickelhaupt reported the pyrolysis of pyridine-2biphenylylborane to yield the pyridine adduct of 9-borafluorene $(\mathbf{D} ; \mathrm{R}=\mathrm{H}) .{ }^{58}$ The authors provided IR spectroscopic data, a mass spectrum and a combustion analysis of their compound. Finally, Nöth et al. published the X-ray crystal structure determination of the 9-borafluorene-hydride adduct $\left[\mathrm{C}_{12} \mathrm{H}_{8} \mathrm{BH}_{2}\right]^{-59}$ Parent 9,10-dihydro-9,10-diboraanthracene (E; $\mathrm{R}=\mathrm{H}, \mathrm{X}=\mathrm{BH}$ ) was unmentioned in the literature until 2009.

\subsection{9,10-Dihydro-9,10-diboraanthracene}

To date, two different synthesis protocols for 9,10-dihydro-9,10diboraanthracene (5) have been developed (Scheme 2). One starts from 9,10-dibromo-9,10-dihydro-9,10-diboraanthracene (4) and uses $\mathrm{Et}_{3} \mathrm{SiH}$ as hydride transfer reagent, ${ }^{60,61}$ the other introduces the hydrogen substituents prior to the assembly of the diboraanthracene scaffold. ${ }^{31}$ Mechanistically, the latter case is particularly revealing, because treatment of the aryl(trihydro)borate 6 with $\mathrm{Me}_{3} \mathrm{SiCl}$ gives the aryl(dihydro)borane \{1,2$\left.\mathrm{C}_{6} \mathrm{H}_{4}\left(\mathrm{BH}_{2}\right)_{2}\right\}$, which subsequently undergoes a ligand redistribution reaction to form the unsymmetrically substituted diborane(6) derivative $\mathbf{5}\left(\mathrm{BH}_{3}\right)_{2}$. The intermediacy of $\left\{1,2-\mathrm{C}_{6} \mathrm{H}_{4}\left(\mathrm{BH}_{2}\right)_{2}\right\}$ has been probed by trapping experiments with various $\mathrm{N}$-donors, which lead to isolable $\mathrm{B}-\mathrm{N}$ adducts (as in the case of 3; Scheme 1). ${ }^{31}$ In the absence of Lewis bases, the cyclisation reaction $\mathbf{6} \rightarrow \mathbf{5}\left(\mathrm{BH}_{3}\right)_{2}$ occurs already at room temperature, thereby testifying to the high potential of directed substituent scrambling reactions for the synthesis of complex organoborane frameworks (Scheme 2). From a practical point of view, the synthesis of 5 from 4 is preferable, because the target molecule is obtained without adducted $\left\{\mathrm{BH}_{3}\right\}$ and the yields are higher. A monotopic relative $\mathbf{7}$ of the ditopic borane $\mathbf{5}$ has been synthesised after blocking one boron atom of the tricyclic scaffold with a sterically demanding mesityl substituent (Scheme 2). ${ }^{62}$

Similar to most other diaryl(hydro)boranes (except $\operatorname{Trip}_{2} \mathrm{BH}$ ), 9,10-dihydro-9,10-diboraanthracene (5) tends to involve its B-H functionalities into B-H-B three-centre, two-electron $(3 \mathrm{c}-2 \mathrm{e})$ bonding. Since $\mathbf{5}$ is a ditopic hydroborane, a polymeric solidstate structure $(\mathbf{5})_{n}$ results, which is as of yet unparalleled in macromolecular chemistry (Fig. 3) ${ }^{60}$ Each of the repeating units in $(\mathbf{5})_{n}$ adopts a folded boat conformation with a dihedral angle of $\varphi=134^{\circ}$. The folded conformation of the $\mathrm{C}_{12} \mathrm{H}_{8} \mathrm{~B}_{2}$ fragments probably has no electronic reason, but is a precondition for the assembly of an unstrained polymer backbone: if the 9,10dihydro-9,10-diboraanthracene units in $(\mathbf{5})_{n}$ were planar, the planes of adjacent moieties would have to be twisted with respect to each other in order to provide sufficient room for the hydrogen atoms at $\mathrm{C}(1), \mathrm{C}(4), \mathrm{C}(5)$ and $\mathrm{C}(8)$. The consequence would be a poorer orbital overlap within the $\mathrm{B}-\mathrm{H}-\mathrm{B}$ bridges and thus a weaker linkage. In line with this interpretation, the $\mathrm{X}$-ray crystal structure analysis of the uncongested $\left\{\mathrm{BH}_{3}\right\}$ adduct $\mathbf{5}\left(\mathrm{BH}_{3}\right)_{2}$ shows a perfectly planar framework (Fig. 3). ${ }^{31}$ The monotopic borane 7 exists as a dimer $(7)_{2}$ in the crystal lattice (Fig. 3). ${ }^{62}$ Its two 9,10-dihydro-9,10-diboraanthracene halves deviate from planarity $\left(\varphi=147^{\circ}\right)$, but to a lesser degree than in $(\mathbf{5})_{n}$. Moreover, the simultaneous presence of tri- and tetracoordinate boron centres results in a puckering of the central six-membered ring. In contrast to the solid state, monomeric 7 is prevalent in benzene solution. According to DFT calculations, the dimerisation of 9,10-dihydro-9,10-diboraanthracene (5) is essentially thermoneutral under gas-phase conditions, whereas the addition of a third monomer to the dimer is an exothermic process. It has therefore been suggested that the polymerisation of $\mathbf{5}$ is due to a positive binding cooperativity, because increasing 


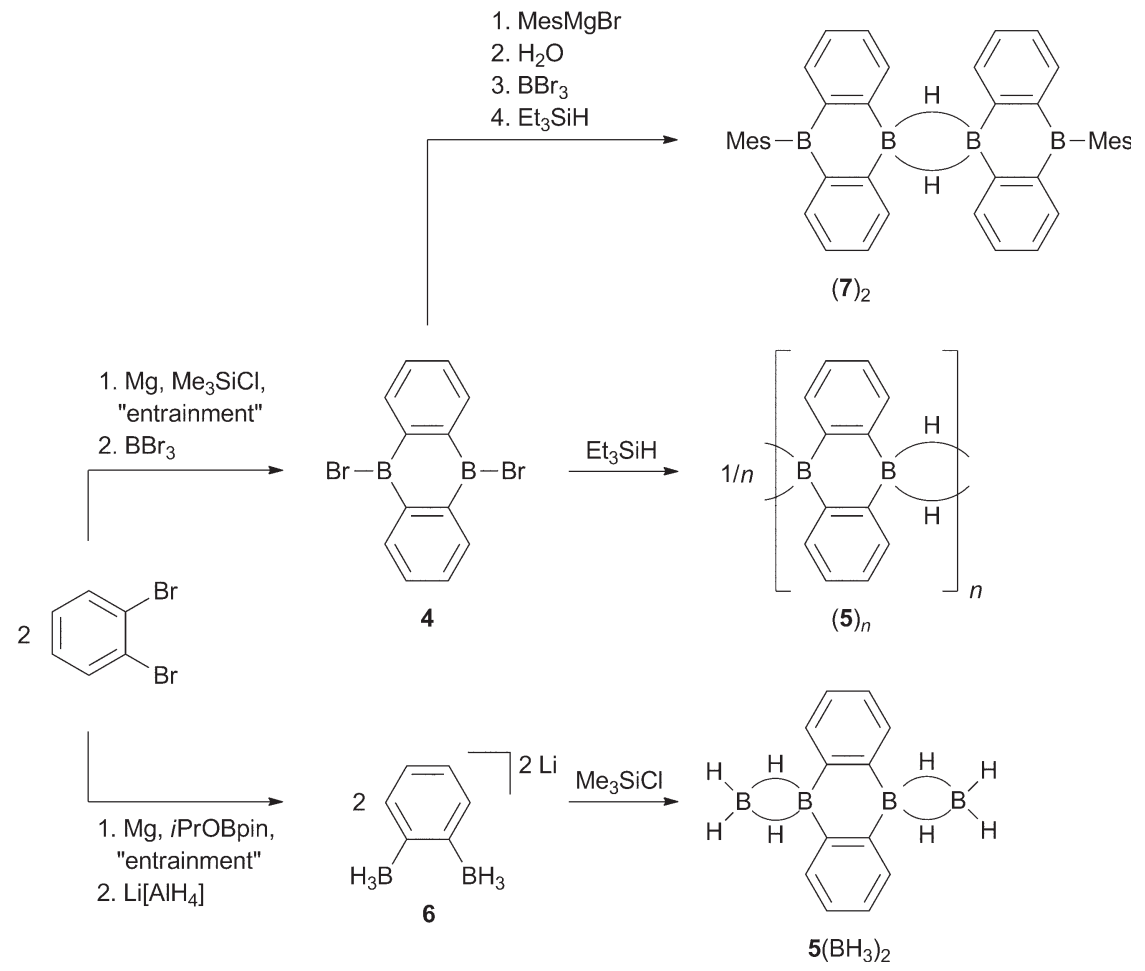

Scheme 2 Synthesis of parent 9,10-dihydro-9,10-diboraanthracene $(\mathbf{5})_{n}$, its $\left\{\mathrm{BH}_{3}\right\}$ adduct $\mathbf{5}\left(\mathrm{BH}_{3}\right)_{2}$ and the monotopic congener (7) 2 .

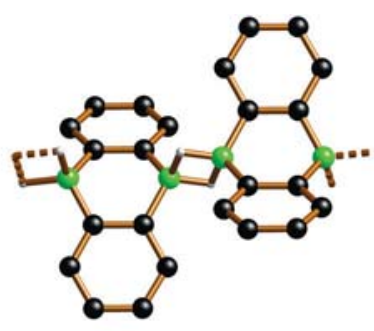

$(5)_{n}$
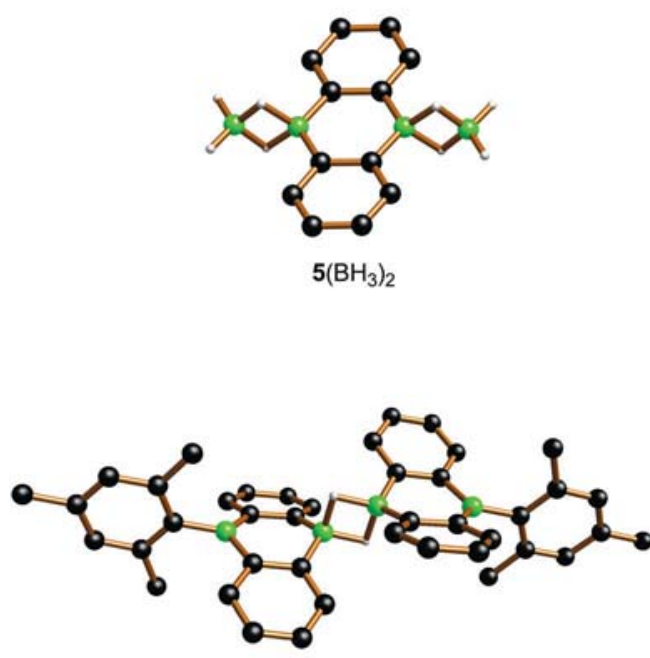

$(7)_{2}$

Fig. 3 Comparison of the solid-state structures of $(\mathbf{5})_{n}, \mathbf{5}\left(\mathrm{BH}_{3}\right)_{2}$ and $(7)_{2}$ (hydrogen atoms attached to carbon atoms omitted for clarity). chain lengths are accompanied by a lower proportion of strained, puckered end groups. $^{60}$

Monomeric 9,10-dihydro-9,10-diboraanthracene (5) can be stabilised (i) by two-electron reduction $\left(c f . \mathrm{Li}_{2}[\mathbf{5}] \text {; Scheme } 3\right)^{63}$ or (ii) by Lewis acid-base pairing with pyridine or $\mathrm{SMe}_{2}$ ( $c f$. $\mathbf{5}\left(\mathrm{SMe}_{2}\right)_{2} ;$ Scheme 3). ${ }^{64}$

The availability of the isolable anion $[5]^{2-}$ allows to address an interesting question: the commonly accepted mechanism of alkene/alkyne hydroboration postulates a concerted syn addition of $\mathrm{B}$ and $\mathrm{H}$ across the unsaturated bond. Such a process is only possible if the boron atom has a vacant $\mathrm{p}_{z}$ orbital for interaction with the organic $\pi$ system. Dimeric reagents $\mathrm{R}_{2} \mathrm{~B}-(\mu-\mathrm{H})_{2}-\mathrm{BR}_{2}$ as well as donor adducts $\mathrm{R}_{2} \mathrm{~B}(\mathrm{H})$-Do therefore need to dissociate before the hydroboration reaction can take place. The situation for $[5]^{2-}$ is different compared to $\mathrm{R}_{2} \mathrm{~B}-(\mu-\mathrm{H})_{2}-\mathrm{BR}_{2}$ and $\mathrm{R}_{2} \mathrm{~B}(\mathrm{H})-$ Do, because $[5]^{2-}$ is not bonded to a second molecule and therefore its boron atoms are still tricoordinated. Nevertheless, its boron-centred $\mathrm{p}_{z}$ orbitals are occupied by the extra electrons. How does this affect the reactivity of $[5]^{2-}$ towards polar and nonpolar multiple bonds? The limited experimental evidence available so far suggests that a two-electron reduction of $\mathbf{5}$ shuts down any hydroboration reactivity. With di( $p$-tolyl)ketone, $[\mathbf{5}]^{2-}$ undergoes a 1,4-addition reaction, as it is typical for the isoelectronic congener anthracene (cf. 8; Scheme 3 ). When $[\mathbf{5}]^{2-}$ is treated with $\mathrm{HC} \equiv \mathrm{C} t \mathrm{Bu}$, a formal $\mathrm{C}-\mathrm{H}$ activation instead of a hydroboration reaction occurs ( $c f .9$; Scheme 3 ). In the presence of excess $\mathrm{HC} \equiv \mathrm{C} t \mathrm{Bu}$, a slow follow-up process leads to the introduction of an alkynyl group also at the second boron atom (10; Scheme 3). Liberation of $\mathrm{H}_{2}$ indicates basically a Brønstedt acid-base neutralisation process. ${ }^{63}$ It is worth mentioning that the reaction $\mathrm{Li}_{2}[5] \rightarrow 9$ offers a way to unsymmetrically 

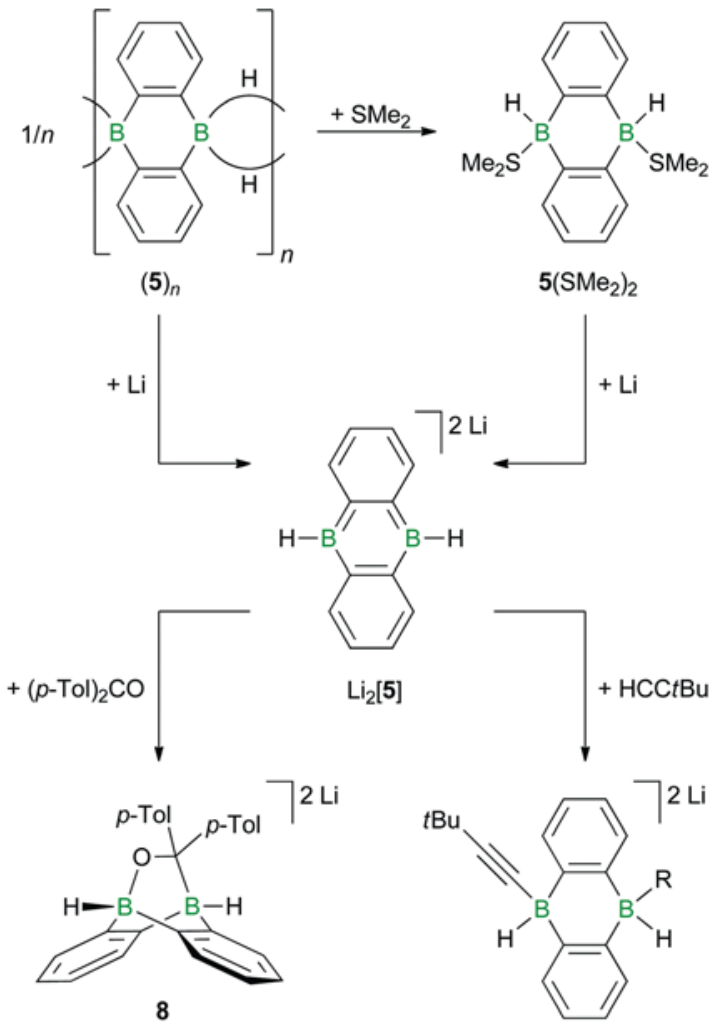

$\left(\mathrm{SMe}_{2}\right)_{2}$
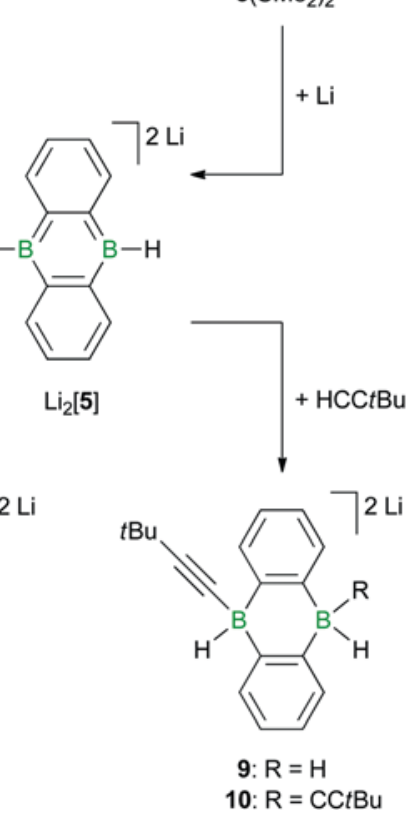

Scheme 3 Transformation of polymeric $(\mathbf{5})_{n}$ into monomeric species through adduct formation $\left(\mathbf{5}\left(\mathrm{SMe}_{2}\right)_{2}\right)$ or two-electron reduction $\left(\mathrm{Li}_{2}[\mathbf{5}]\right)$; 1,4-addition reaction of $\mathrm{Li}_{2}[\mathbf{5}]$ with $(p-\mathrm{Tol})_{2} \mathrm{CO}$ and $\mathrm{C}-\mathrm{H}$ activation reaction with $\mathrm{HC} \equiv \mathrm{C} t \mathrm{Bu}$.

substituted 9,10-dihydro-9,10-diboraanthracenes, which considerably broadens the synthetic potential of these building blocks ( $c f$. also $(7)_{2}$; Scheme 2).

The pyridine and the $\mathrm{SMe}_{2}$ diadducts of 9,10-dihydro-9,10diboraanthracene (5) have been characterised by X-ray crystallography. ${ }^{64}$ In the former compound, both pyridine ligands are fixed in a mutual anti configuration; the two $\mathrm{SMe}_{2}$ ligands in the latter molecule, however, are attached in a syn fashion to the molecular plane. Syn coordination is the only possible binding mode when 1,2-diazine donors like pyridazine, phthalazine (pta) or pyrazolide are used. The resulting B-N analogues of benzotriptycene (e.g., 5(pta); Scheme 4) are remarkable on the following grounds: (i) Competition experiments between phthalazine and the more electron-rich pyridine resulted in the exclusive formation of the bridged species 5(pta). (ii) Compounds like 5(pta) are comparatively inert towards air and moisture. Since adduct formation with 1,2-diazenes is not restricted to parent $\mathbf{5}$, but readily takes place also with the analogous $\mathrm{B}-\mathrm{R}$ derivatives $(\mathrm{R}=$ alkenyl, alkynyl), ditopic Lewis bases can be used as protective groups for otherwise unstable 9,10-dihydro-9,10-diboraanthracenes. (iii) 9,10-Dimethyl-9,10-dihydro-9,10-diboraanthracene has been shown to act as an efficient catalyst for the activation of phthalazine in inverse electron-demand Diels-Alder reactions (Scheme 4). The key intermediate of the catalytic cycle is a 5(pta)-type 1:1 complex. $^{65,66}$ Carried out in a stoichiometric

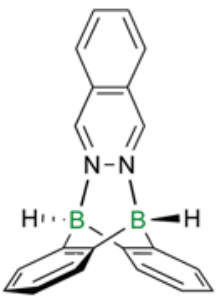

5 (pta)<smiles>[R]C=C([R])N1CCCC1</smiles><smiles>[R]c1cc2ccccc2cc1[R]</smiles>

Scheme 4 The benzotriptycene-like phthalazine adduct $\mathbf{5}$ (pta) and the role of related species in 9,10-dihydro-9,10-diboraanthracene-catalysed Diels-Alder reactions.

fashion, this reaction also provides a perspective for the deprotection step in the above-mentioned protective group chemistry.

\subsection{9-Borafluorene}

Similar to the 9,10-dihydro-9,10-diboraanthracene derivatives $\mathbf{5}$ and 7, 9-borafluorene (12) readily forms from 9-bromo-9-borafluorene (11) ${ }^{67}$ and $\mathrm{Et}_{3} \mathrm{SiH}$ through $\mathrm{Br} / \mathrm{H}$ exchange. ${ }^{68}$ Unlike all other diorganyl(hydro)boranes known to date, $\mathbf{1 2}$ is neither monomeric nor does it exist as doubly B-H-B bridged dimer $(\mathbf{1 2})_{2}{ }^{\mathrm{b}}$ in non-donor solvents (Scheme 5). According to NMR spectroscopy and the results of quantum-chemical calculations, two molecules of $\mathbf{1 2}$ rather establish a unique $C_{1}$-symmetric structure $(\mathbf{1 2})_{2}{ }^{\mathrm{a}}$ bearing one hydrogen atom and one phenyl ring in bridging positions. ${ }^{68}$ The only molecule establishing a comparable structural motif, albeit with tricoordinate boron atoms, is the mesityl-bridged methyleneborane $\mathbf{1 3}$ (Scheme 5). ${ }^{69}$

$(\mathbf{1 2})_{2}{ }^{\mathrm{a}}$ is not long-term stable in solution, but, in the absence of a reaction partner, undergoes ring-opening oligomerisation instead (see below). The addition of pyridine or $\mathrm{SMe}_{2}$ to freshly prepared samples of $(\mathbf{1 2})_{2}{ }^{a}$ suppresses this oligomerisation reaction and provides the corresponding adducts 12(py) and $\mathbf{1 2}\left(\mathrm{SMe}_{2}\right)$ of 9-borafluorene. 12 ( py) and $\mathbf{1 2}\left(\mathrm{SMe}_{2}\right)$ have been isolated and fully characterised (Scheme 5). ${ }^{68,70}$ With 0.5 equivalents of $\mathrm{HC} \equiv \mathrm{C} t \mathrm{Bu},(\mathbf{1 2})_{2}{ }^{a}$ readily reacts to the 1,1-diborylalkane 14 (Scheme 5). ${ }^{68}$ The tendency of in situ generated $(\mathbf{1 2})_{2}{ }^{\mathrm{a}}$ to undergo a double hydroboration reaction is high and the single hydroboration product $\mathrm{C}_{12} \mathrm{H}_{8} \mathrm{BC}(\mathrm{H})=\mathrm{C}(\mathrm{H}) t \mathrm{Bu}$ is therefore 


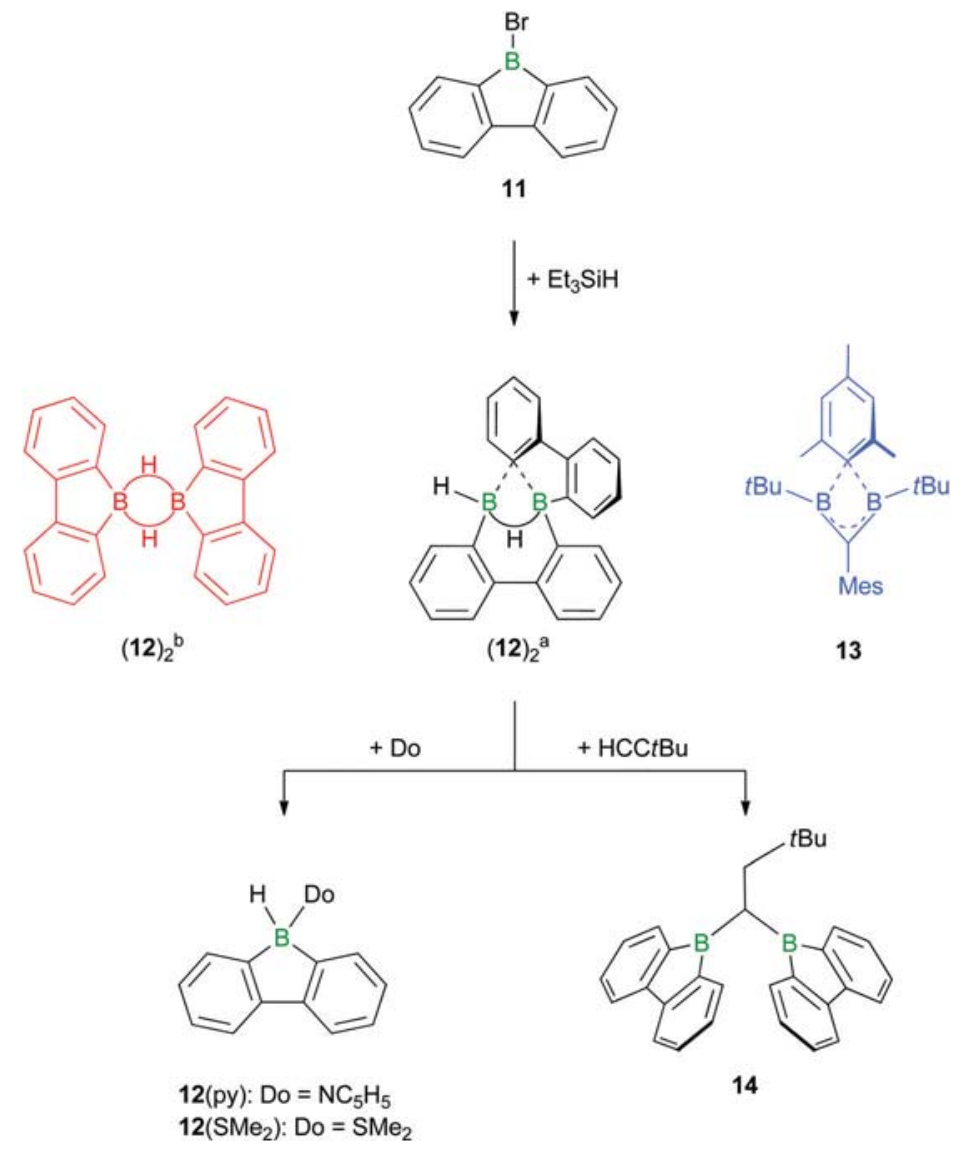

Scheme 5 The synthesis of parent 9-borafluorene (12), its unusual dimeric structure (12) ${ }_{2}{ }^{\mathrm{a}}$ compared to the non-existent conventional dimer (12) ${ }_{2}{ }^{\mathrm{b}}$ (red) and the B-C-B-bridged reference species 13 (blue). Reactivity of $(\mathbf{1 2})_{2}{ }^{a}$ towards selected Lewis bases and $\mathrm{HC} \equiv \mathrm{C} t \mathrm{Bu}$.

difficult to obtain in pure form from this starting material $\left(\mathrm{C}_{12} \mathrm{H}_{8} \mathrm{~B}=\right.$ 9-borafluorenyl $)$. In contrast, the $\mathrm{SMe}_{2}$ adduct $\mathbf{1 2}\left(\mathrm{SMe}_{2}\right)$ was found to be a much more selective hydroboration reagent and, depending on the stoichiometry employed, provides convenient access to either $\mathbf{1 4}$ or $\mathrm{C}_{12} \mathrm{H}_{8} \mathrm{BC}(\mathrm{H})=\mathrm{C}(\mathrm{H}) t \mathrm{Bu} .^{70}$

In the experiments summarised above, $(\mathbf{1 2})_{2}{ }^{\mathrm{a}}$ behaved towards Lewis bases and terminal alkynes as one would have expected from the non-existent symmetric dimer $(\mathbf{1 2})_{2}{ }^{\mathrm{b}}$. This observation can be rationalised by a closer inspection of the calculated molecular structure of $(\mathbf{1 2})_{2}{ }^{\mathrm{a}}$, which reveals one fragment (shown in grey in Scheme 6) that still contains a central five-membered ring and therefore has largely maintained the original borafluorene framework. The second fragment (shown in red in Scheme 6) features a central six-membered ring and is related to 1,2-(2,2'-biphenylylene)diborane(6) (15). ${ }^{70,71}$ Treatment of $\mathbf{1 5}$ with the electron-pair donor $\mathrm{SMe}_{2}$ results in a ring-contraction reaction and yields equal amounts of $\mathbf{1 2}\left(\mathrm{SMe}_{2}\right)$ and $\mathrm{Me}_{2} \mathrm{~S}-$ $\mathrm{BH}_{3}{ }^{70}$ It is therefore plausible that a similar process gives back two equivalents of 9-borafluorene (12) when $\mathrm{SMe}_{2}$ or pyridine are added to the dimer $(\mathbf{1 2})_{2}{ }^{\mathrm{a}}$. Interestingly, the extrusion of $\left\{\mathrm{BH}_{3}\right\}$ from 1,2-(2,2'-biphenylylene)diborane(6) (15) appears to be a reversible process, because Chung et al. obtained $\mathbf{1 5}$ as the product of the reaction between 9-chloro-9-borafluorene and $\mathrm{Na}\left[\mathrm{BH}_{4}\right] .{ }^{72}$ In related studies, Köster and Wrackmeyer came to the conclusion that 9-ethyl-9-borafluorene (16) reversibly inserts $\left\{\mathrm{H}_{2} \mathrm{BEt}\right\}$ under formation of 1,2-diethyl-1,2-(2,2'-biphenyl- ylene)-diborane(6) (17; Scheme 6). ${ }^{71,73}$ Moreover, 17 and 2 equivalents of $\mathrm{H}_{2} \mathrm{C}=\mathrm{CH}_{2}$ give 16 and $\mathrm{BEt}_{3}$ in a manner reminiscent of the reaction between $(\mathbf{1 2})_{2}{ }^{\mathrm{a}}$ and $\mathrm{HC} \equiv \mathrm{C} t \mathrm{Bu}$.

The chemistry surveyed up to this point raises the question why the 9,10-dihydro-9,10-diboraanthracene derivatives $\mathbf{5}$ and $\mathbf{7}$ form conventional, doubly B-H-B bridged oligomers $(\mathbf{5})_{n}$ and $(\mathbf{7})_{2}$ whereas 9-borafluorene (12) dimerises to $(\mathbf{1 2})_{2}{ }^{\mathrm{a}}$ with opening of one boron heterocycle. One reason might be that the central rings in $\mathbf{5}$ on the one hand and $\mathbf{1 2}$ on the other have different degrees of antiaromaticity. Unfortunately, the subtleties of the electronic structures of $\mathbf{5} v s . \mathbf{1 2}$ have so far not been investigated in any detail and it is therefore difficult to judge the validity of this argument. We note, however, that also the fully saturated species 1,2-tetramethylenediborane(6) (18; Scheme 6) and 1,2:1,2-bis(tetramethylene)diborane(6) (19; Scheme 6) possess the structures $18^{\mathrm{a}} / \mathbf{1 9}^{\mathrm{a}}$ rather than $\mathbf{1 8}^{\mathrm{b}} / \mathbf{1 9}^{\mathrm{b}}{ }^{74}$ Since any influence of $\pi$ electrons can obviously be excluded in these cases, effects of ring size and ring strain are likely to play a role, too (the 9,10-dihydro-9,10-diboraanthracene exo-adduct $\mathbf{5}\left(\mathrm{BH}_{3}\right)_{2}$ corresponds to $\left.\mathbf{1 8}^{\mathrm{b}}\right) .^{75}$

\subsection{Ferrocenyl(hydro)boranes}

Two different ferrocenyl(hydro)boranes, i.e. $\{\mathrm{FcB}(\mathrm{H}) \mathrm{Br}\}$ $(\mathbf{2 1})^{76,77}$ and $\left\{\mathrm{FcBH}_{2}\right\}$ (23), ${ }^{78-80}$ have been prepared from $\mathrm{FcBBr}_{2}(\mathbf{2 0})$ by $\mathrm{Br} / \mathrm{H}$ exchange and from $\mathrm{Li}\left[\mathrm{FcBH}_{3}\right]$ (22) by 


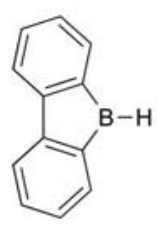

12

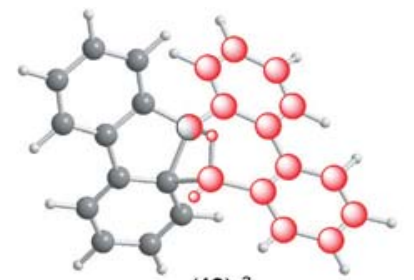

$(12)_{2}{ }^{\mathrm{a}}$

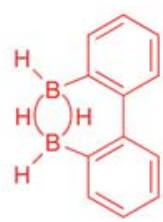

15

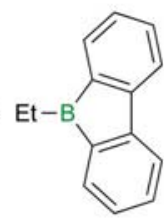

12( $\left.\mathrm{SMe}_{2}\right)$
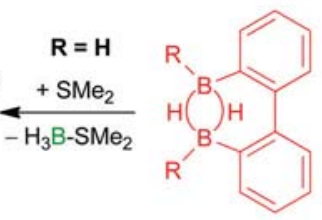

15: $R=H$ 16

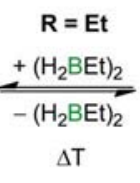

$\Delta \mathrm{T}$

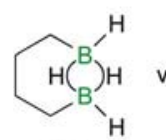

$18^{a}$

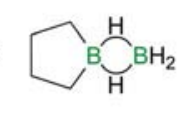

$18^{b}$

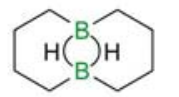

$19^{a}$

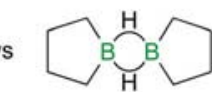

$19^{b}$

Scheme 6 Structural comparison of $(\mathbf{1 2})_{2}{ }^{\mathrm{a}}$ with monomeric 9-borafluorene (12) and 1,2-(2,2'-biphenylylene)diborane(6) (15); Lewis baseor temperature-induced ring-contraction reactions of 1,2-(2,2'-biphenylylene)diboranes(6); conceivable isomers of $\left(\mathrm{CH}_{2}\right)_{4} \mathrm{BH} \cdot \mathrm{BH}_{3}(\mathbf{1 8})$ and of $\left(\left(\mathrm{CH}_{2}\right)_{4} \mathrm{BH}\right)_{2}(\mathbf{1 9})$.

hydride elimination, respectively ( $\mathrm{Fc}=$ ferrocenyl; Scheme 7). In contrast to 9,10 -dihydro-9,10-diboraanthracene $(\mathbf{5})_{n}$, which is fully stable under inert conditions, ${ }^{60}$ and 9-borafluorene $(\mathbf{1 2})_{2}{ }^{\mathrm{a}}$, which persists long enough in solution to allow its NMR spectroscopic characterisation, ${ }^{68} \mathbf{2 1}$ and $\mathbf{2 3}$ are only transient species. Their existence as reaction intermediates has been postulated mainly on the basis of DFT calculations (21) and of trapping studies, which gave the crystallographically characterised adducts $23\left(\mathrm{NMe}_{2} \mathrm{Et}\right)^{78}$ and $\mathbf{2 3}\left(\mathrm{SMe}_{2}\right){ }^{80}$ In the absence of Lewis bases, the final, isolable products of both reaction sequences are $\mathrm{Fc}_{2} \mathrm{BBr}(\mathbf{2 4})^{76,77}$ and monomeric $\mathrm{Fc}_{2} \mathrm{BH}(\mathbf{2 5}){ }^{78}$ together with $\mathrm{B}_{2} \mathrm{H}_{6}$ (Scheme 7). The monomeric nature of $\mathbf{2 5}$ has been attributed, at least in part, to an intramolecular electronic $\mathrm{Fe} \cdots \mathrm{B}$ through-space interaction. ${ }^{78,79,81,82}$

The underlying mechanism of the two condensation reactions is a highly selective substituent redistribution process: $\mathrm{Fc}_{2} \mathrm{BBr}$ (24) was obtained in almost $90 \%$ yield, far better than the yield of the more conventional metathesis reaction between $\mathrm{FcBBr}_{2}$ (20) and $\mathrm{FcSnMe}_{3}(58 \%)$. ${ }^{76}$ No alternative synthesis route to that described in Scheme 7 is known to the literature for $\mathrm{Fc}_{2} \mathrm{BH}$ (77\% yield). ${ }^{78}$

The fact that the boron atoms of $\mathbf{2 1 / 2 3}$ are not embedded into cyclic structures could explain why $\mathbf{2 1 / 2 3}$ proved less stable and more prone to substituent scrambling than the aryl(hydro)boranes 5 and 12. Increasing the steric bulk of the reactants by switching from $\mathrm{FcBBr}_{2}$ to $\mathrm{Fc}^{\#} \mathrm{BBr}_{2}\left(\mathrm{Fc}^{\#}=1^{\prime}, 2^{\prime}, 3^{\prime}, 4^{\prime}, 5^{\prime}\right.$-pentamethylferrocenyl) significantly slows down the condensation reaction, but not to an extent that would allow the unambiguous
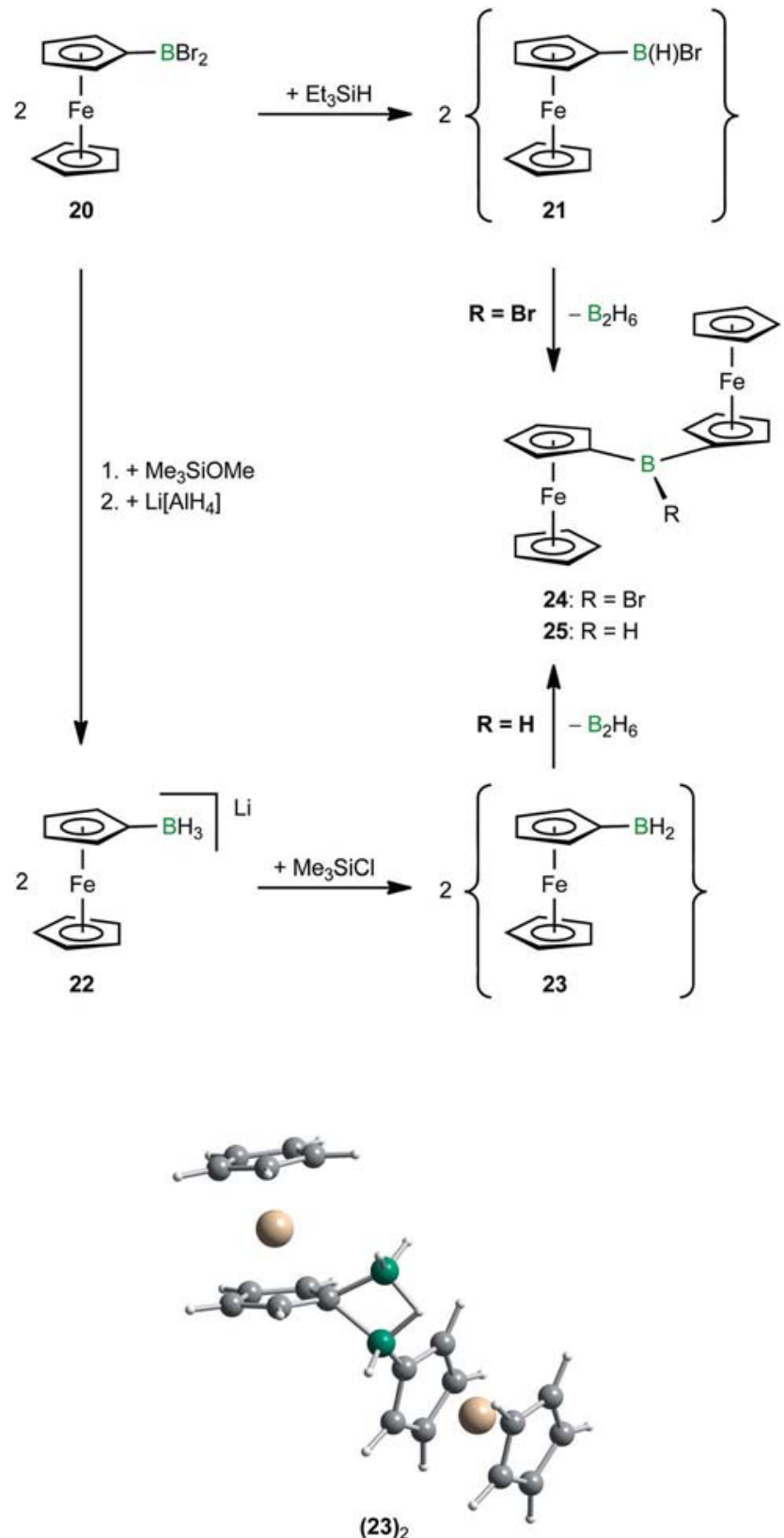

Scheme 7 Synthesis of the transient ferrocenyl(hydro)boranes $\mathbf{2 1}$ and 23 and their condensation (i.e. substituent redistribution) reactions to the diferrocenylboranes $\mathbf{2 4}$ and $\mathbf{2 5}$; calculated intermediate $(\mathbf{2 3})_{2}$ of the substituent redistribution of $\mathbf{2 3}$. Note: the condensation reaction $\mathbf{2 1} \rightarrow \mathbf{2 4}$ yields $\left\{\mathrm{BH}_{2} \mathrm{Br}\right\}$ as the primary byproduct, which reacts further with excess $\mathrm{Et}_{3} \mathrm{SiH}$ to $\mathrm{B}_{2} \mathrm{H}_{6}$.

identification of intermediate $\left\{\mathrm{Fc}^{\#} \mathrm{~B}(\mathrm{H}) \mathrm{Br}\right\}$ in the mixture. ${ }^{83}$ Similar to the ferrocenyl(dibromo)boranes, $\mathrm{CymBBr}_{2}$ transforms to $\mathrm{Cym}_{2} \mathrm{BBr}$ upon addition of $\mathrm{Et}_{3} \mathrm{SiH}(\mathrm{Cym}=$ cymantrenyl $) .{ }^{83}$ In stark contrast to the ferrocenyl species, it is also feasible to generate and crystallise the dimeric dihydroborane $\left(\mathrm{CymBH}_{2}\right)_{2}$ at low temperatures, even though $\left\{\mathrm{CymBH}_{2}\right\}$ does not have a cyclic framework. ${ }^{83}$ The organometallic substituent needs to adopt a bridging position between two boron atoms in the intermediate state of the condensation reaction ( $c f$. the calculated intermediate $(\mathbf{2 3})_{2}$ of the scrambling reaction of $\mathbf{2 3}$ showing the 
same key features as $(\mathbf{1 2})_{2}{ }^{a}$; Schemes 6 and 7). It is therefore reasonable to assume that the conversion rate should decrease with decreasing electron density on the respective cyclopentadienyl ring (i.e. upon going from $\mathrm{Fc}$ to $\mathrm{Cym}$ ). However, this working hypothesis does not account for the ability of pentafluorophenyl(hydro)boranes $\left(\mathrm{C}_{6} \mathrm{~F}_{5}\right)_{n} \mathrm{BH}_{3-n}$ to readily undergo substituent scrambling. ${ }^{43}$ We therefore conclude that the electronic factors governing the exchange reaction are so far not fully understood. ${ }^{84}$

Investigations into the hydroboration reactivity of ferrocenyl(hydro)boranes showed that $23\left(\mathrm{NMe}_{2} \mathrm{Et}\right.$ ) adds two equivalents of $\mathrm{HC} \equiv \mathrm{C} t \mathrm{Bu}$ to give the divinylborane $\mathrm{FcB}(\mathrm{C}(\mathrm{H})=\mathrm{C}(\mathrm{H}) t \mathrm{Bu})_{2}$ at elevated temperatures. ${ }^{78}$ Hydroboration of $\mathrm{HC} \equiv \mathrm{C} t \mathrm{Bu}$ with $\mathbf{2 5}$ requires shorter times and lower temperatures for the quantitative formation of $\mathrm{Fc}_{2} \mathrm{BC}(\mathrm{H})=\mathrm{C}(\mathrm{H}) t \mathrm{Bu} .^{78,80}$ The in situ generation of $\mathrm{FcBH}_{2}(\mathbf{2 3})$ in the presence of cyclohexene provides $\mathrm{Fc}_{2} \mathrm{BCy}$ and $\mathrm{BCy}_{3}$ but no $\mathrm{FcBCy}_{2}$, thereby indicating that 23 undergoes condensation to $\mathbf{2 5}$ more quickly than hydroboration of an internal olefin can occur $(\mathrm{Cy}=$ cyclohexyl $){ }^{80}$

\section{Polymerisation reactions of aryl(hydro)boranes}

\subsection{Hydroboration (polymerisation) reactions of} 9,10-dihydro-9,10-diboraanthracene

9,10-Dihydro-9,10-diboraanthracene is a potent hydroboration reagent. It readily adds across the $\mathrm{C} \equiv \mathrm{C}$ triple bonds of alkynes already at room temperature within minutes and without the need for a catalyst. The reaction can be carried out either under heterogeneous conditions using $(\mathbf{5})_{n}$ or in homogeneous solution employing $\mathbf{5}\left(\mathrm{SMe}_{2}\right)_{2}$. With $\mathrm{HC} \equiv \mathrm{C} t \mathrm{Bu}$ as the reaction partner, the corresponding vinylborane $t \mathrm{BuC}(\mathrm{H})=\mathrm{C}(\mathrm{H}) \mathrm{B}\left(o-\mathrm{C}_{6} \mathrm{H}_{4}\right)_{2} \mathrm{BC}$ $(\mathrm{H})=\mathrm{C}(\mathrm{H}) t \mathrm{Bu}$ has been obtained in essentially quantitative yield. ${ }^{60}$ Contrary to that, the para-phenylacetylenes $\mathrm{HC} \equiv \mathrm{C}(p$ $\left.\mathrm{C}_{6} \mathrm{H}_{4} \mathrm{Me}\right)$ and $\mathrm{HC} \equiv \mathrm{C}\left(p-\mathrm{C}_{6} \mathrm{H}_{4} \mathrm{NMe}_{2}\right)$ gave mixtures of several products from which the target compounds $\mathbf{2 6}$ and $\mathbf{2 7}$ have been isolated (Fig. 4) ${ }^{85}$ Further insight into the chemo- and regioselectivity of hydroboration reactions of 9,10-dihydro-9,10diboraanthracenes was gained with the help of the monotopic model system 7. ${ }^{62}$ The following conclusions are noteworthy: (i) Unwanted double hydroboration of (aryl)alkynes is not an issue; the corresponding vinylboranes are readily accessible. (ii) The regioselectivity of (aryl)alkyne hydroboration becomes a problem only if substituents in the ortho-position to the alkyne groups are absent. For example, the reaction between 7 and $\mathrm{HC} \equiv \mathrm{C}\left(p-\mathrm{C}_{6} \mathrm{H}_{4} \mathrm{Me}\right)$ provided the two isomers $\operatorname{Mes} \mathrm{B}(o-$ $\left.\mathrm{C}_{6} \mathrm{H}_{4}\right)_{2} \mathrm{BC}(\mathrm{H})=\mathrm{C}(\mathrm{H})\left(p-\mathrm{C}_{6} \mathrm{H}_{4} \mathrm{Me}\right)$ and $\mathrm{MesB}\left(o-\mathrm{C}_{6} \mathrm{H}_{4}\right)_{2} \mathrm{BC}(p-$ $\left.\mathrm{C}_{6} \mathrm{H}_{4} \mathrm{Me}\right)=\mathrm{CH}_{2}$ in a $2: 1$ ratio, whereas 7 reacts with $\mathrm{HC} \equiv$ CMes exclusively to $\operatorname{MesB}\left(o-\mathrm{C}_{6} \mathrm{H}_{4}\right)_{2} \mathrm{BC}(\mathrm{H})=\mathrm{C}(\mathrm{H}) \mathrm{Mes}^{62}$

The fluorescence spectra of the two 9,10-dihydro-9,10-diboraanthracene derivatives 26 and 27 (Fig. 4) revealed a pronounced red-shift of the emission maximum upon changing the peripheral substituents from Me to $\mathrm{NMe}_{2}\left(\lambda_{\mathrm{em}}(\mathbf{2 6})=460 \mathrm{~nm} ; \lambda_{\mathrm{em}}(\mathbf{2 7})=\right.$ $570 \mathrm{~nm}$; toluene). ${ }^{85}$ The absolute difference of $\left|\Delta\left(\lambda_{\mathrm{em}}\right)\right|=$ $110 \mathrm{~nm}$ between the emission maxima of $\mathbf{2 6}$ and $\mathbf{2 7}$ is considerably larger than $\left|\Delta\left(\lambda_{\mathrm{em}}\right)\right|=24 \mathrm{~nm}$ for the related compounds $\mathbf{2 8}$ $\left(\lambda_{\mathrm{em}}=398 \mathrm{~nm}\right)$ and $29\left(\lambda_{\mathrm{em}}=422 \mathrm{~nm}\right.$; cyclohexane $){ }^{86}$ Moreover, the comparison of $\mathbf{2 6}$ with $\mathbf{2 8}\left(\left|\Delta\left(\lambda_{\mathrm{em}}\right)\right|=62 \mathrm{~nm}\right)$ or of $\mathbf{2 7}$ with $29\left(\left|\Delta\left(\lambda_{\mathrm{em}}\right)\right|=148 \mathrm{~nm}\right)$ clearly indicates that switching from

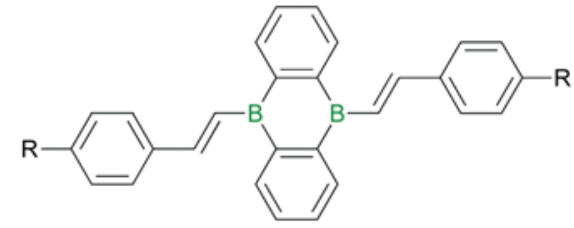

26: $\mathrm{R}=\mathrm{Me}$

27: $\mathrm{R}=\mathrm{NMe}_{2}$

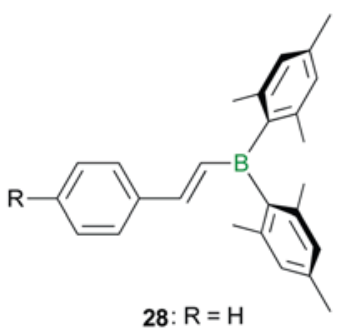

29: $\mathrm{R}=\mathrm{NMe}_{2}$

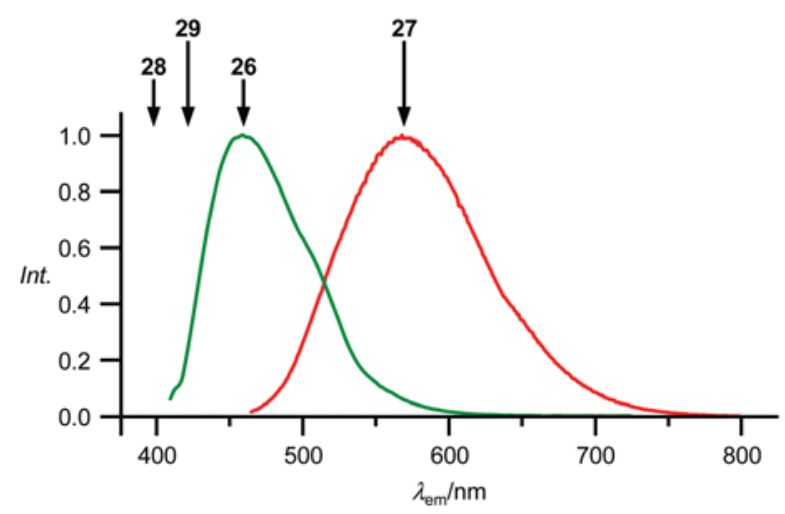

Fig. 4 Two hydroboration products of 9,10-dihydro-9,10-diboraanthracene $(26 / 27)$ and dimesitylborane $(28 / 29)$ and a comparison of their emission spectra.

the $\mathrm{Mes}_{2} \mathrm{~B}$ substituent to the $\mathrm{RB}\left(o-\mathrm{C}_{6} \mathrm{H}_{4}\right)_{2} \mathrm{~B}$ fragment exerts a marked influence on the electronic properties of respective compounds.

Chujo et al. have shown that treatment of aromatic diynes with $\left(\mathrm{MesBH}_{2}\right)_{2}$ or $\left.(\mathrm{TripBH})_{2}\right)_{2}$ offers an elegant route to mainchain boron-doped macromolecules $\mathbf{H}$ via a hydroboration polymerisation process (Scheme 8). ${ }^{87}$ Depending on the choice of the dialkyne, polymeric materials $\mathbf{H}$ exhibiting intense fluorescence, n-type electrical conductivity or third order non-linear optical properties have been prepared. ${ }^{87}$ However, given the very limited number of boranes employed until to date, a variation also of this building block provides room for further development. For the following reasons, 9,10-dihydro-9,10-diboraanthracene (5) is particularly promising in this respect: (i) In $\left\{\mathrm{MesBH}_{2}\right\}$ and $\left\{\mathrm{TripBH}_{2}\right\}$ the two reactive hydrogen atoms are attached to the same boron atom so that the first and the second hydroboration event take place under distinctly different steric and electronic conditions. ${ }^{34,39}$ Compound 5, in contrast, possesses two spatially separated but still electronically coupled B-H units, which should lead to more uniform reactivities and, in turn, to smaller polydispersities and higher molecular weights of the materials produced. (ii) The rigid planar framework of $\mathbf{5}$ 


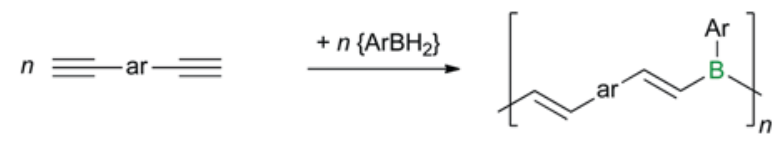

H

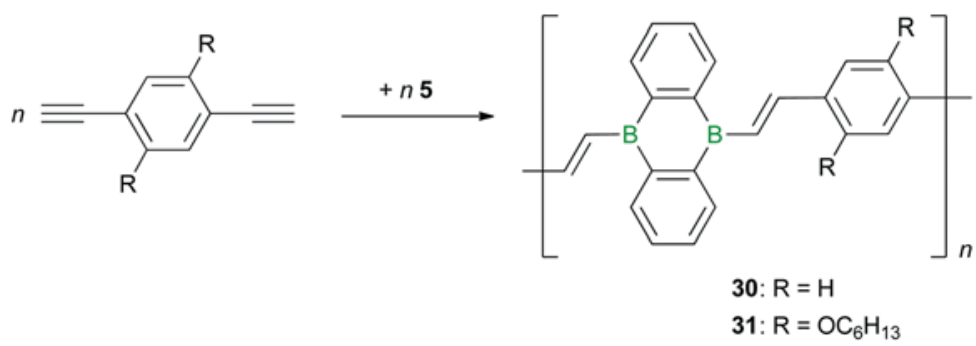

Scheme 8 Hydroboration polymerisation reactions of dialkynes with $\left\{\mathrm{MesBH}_{2}\right\},\left\{\mathrm{TripBH}_{2}\right\}$ and 9,10-dihydro-9,10-diboraanthracene (5); ar = (hetero)arylene, $\mathrm{Ar}=$ Mes, Trip.

warrants continuous optimal $\pi$ delocalisation, renders the compound a reversible two-electron acceptor $\left(c f . \mathrm{Li}_{2}[\mathbf{5}]{ }^{63}\right.$ Scheme 3) and makes 9,10-dihydro-9,10-diboraanthracene-containing (macro)molecules highly redox-active. ${ }^{88,89}$ (iii) 9,10-Dihydro9,10-diboraanthracenes are versatile ligands for transition metal complexes, ${ }^{90,91}$ giving the possibility to decorate corresponding polymers with metal atoms and thereby to modify the optoelectronic properties of the materials.

So far, only the polymers $\mathbf{3 0}$ and $\mathbf{3 1}$ (Scheme 8) have been prepared through hydroboration polymerisation of 1,4-diethynylbenzenes with $\mathbf{5} .^{60,92}$ While $\mathbf{3 0}$ suffers from a generally poor solubility, the introduction of hexyloxy groups turns $\mathbf{3 1}$ into a compound that is well-soluble in common organic solvents. The polymeric structure of $\mathbf{3 1}$ was supported by MALDI-TOF mass spectrometry, which revealed a peak pattern consistent with the expected repeating units of the polymer. ${ }^{60}$

The UV/vis spectrum of $\mathbf{3 1}$ is characterised by a longest wavelength absorption maximum at $410 \mathrm{~nm}$; only small differences were found between the absorption spectra of thin films and solutions of 31. The polymer shows an intense green fluorescence both in toluene solution $\left(\lambda_{\mathrm{em}}=518 \mathrm{~nm}\right)$ and in the solid state. ${ }^{60}$

\subsection{Ring-opening oligomerisation of 9-borafluorene}

In contrast to the ditopic borane 9,10-dihydro-9,10-diboraanthracene (5), the monotopic 9-borafluorene (12) does not qualify for hydroboration polymerisation reactions (even though it is an active hydroboration reagent and can be used to introduce terminal 9-borafluorenyl substituents into extended $\pi$-electron systems). ${ }^{68,70}$ The reactivity of its endocyclic B-C bonds, however, makes 9-borafluorene (12) ideally suited for the development of ring-opening polymerisation protocols. Recently, a corresponding ring-opened pentamer (12) 5 (Fig. 5) has been isolated in high yield from aged mixtures of 9-bromo-9-borafluorene (11) and $\mathrm{Et}_{3} \mathrm{SiH}$ in hexane. ${ }^{68}(\mathbf{1 2})_{5}$ can be viewed as a main-chain boron-doped oligophenylene, the backbone of which is reinforced by four intrastrand $\mathrm{B}-\mathrm{H}-\mathrm{B}$ bridges. The only literature-known macromolecule featuring a related structural motif is

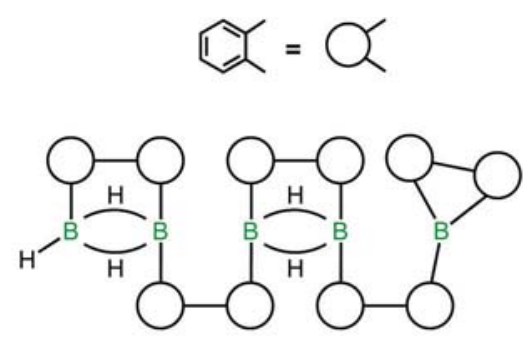

$(12)_{5}$

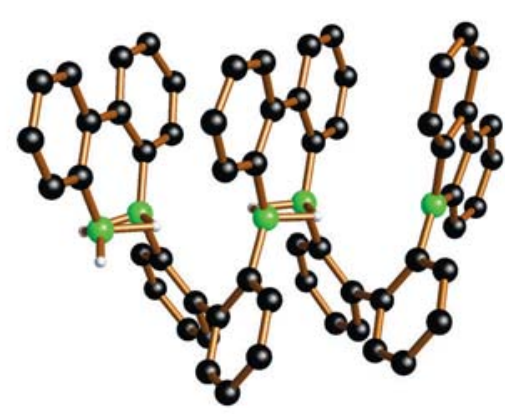

$(12)_{5}$

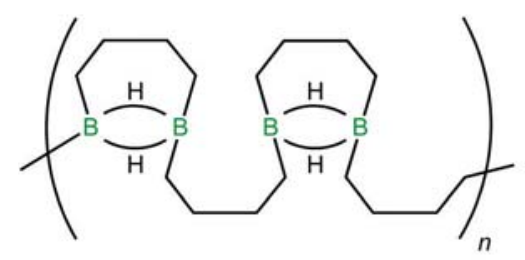

$(32)_{n}$

Fig. 5 The ring-opened pentamer (12) $)_{5}$ of 9-borafluorene (12), its solid-state structure (hydrogen atoms attached to carbon atoms omitted for clarity) and the related polymer $(\mathbf{3 2})_{n}$ featuring a saturated backbone.

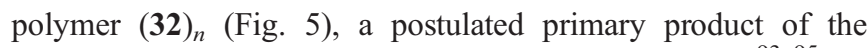
hydroboration reaction between $\mathrm{B}_{2} \mathrm{H}_{6}$ and 1,3-butadiene. ${ }^{93-95}$ 


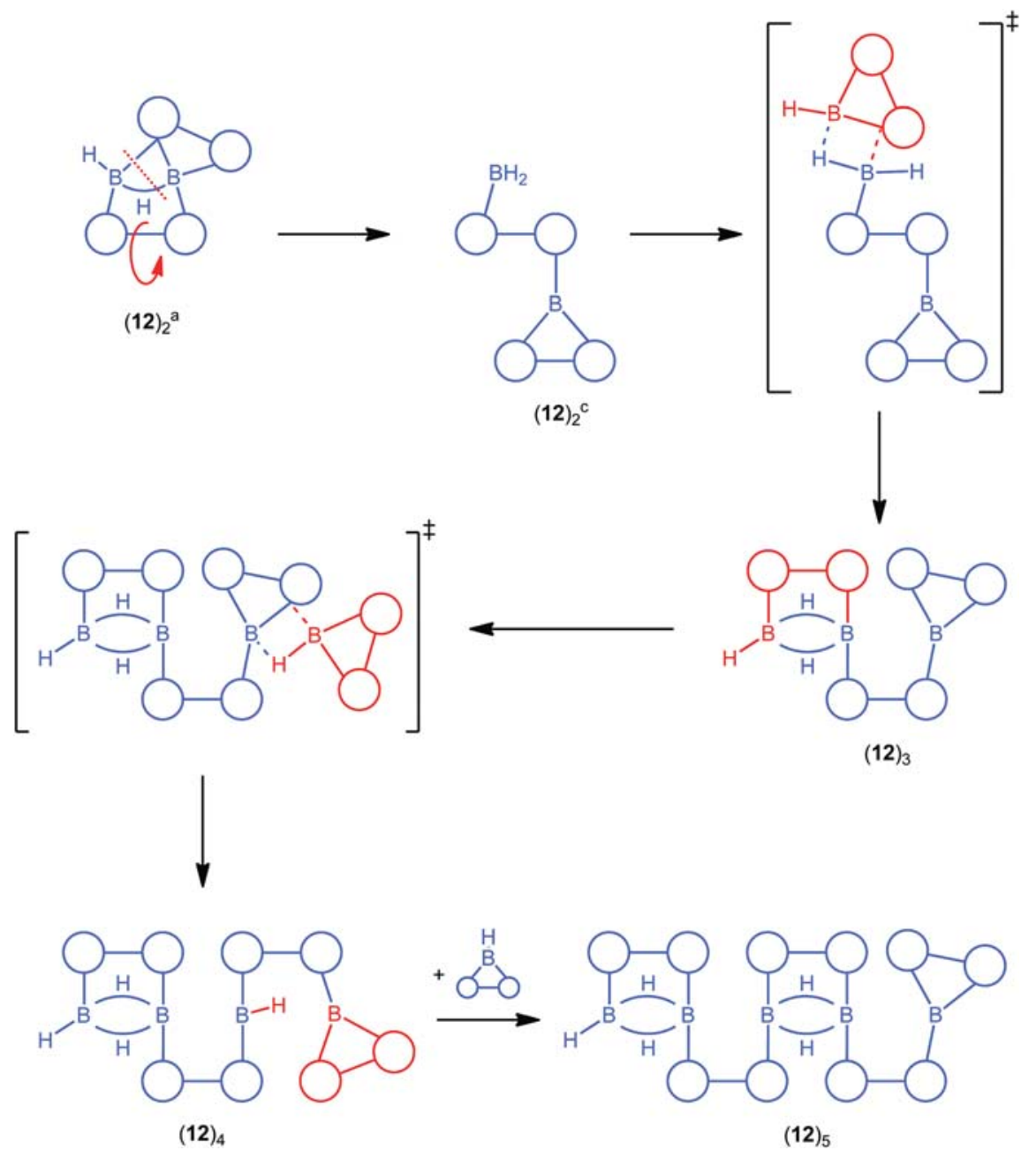

Scheme 9 Mechanism of the ring-opening oligomerisation of 9-borafluorene (12).

The reaction mechanism underlying the formation of $(\mathbf{1 2})_{5}$ has been elucidated by in situ NMR spectroscopy, trapping experiments and quantum-chemical calculations (Scheme 9): ${ }^{68}$ in the first step of the oligomerisation sequence, one B-C bond of a first 9-borafluorene monomer (12) adds across the B-C bond of a second monomer to generate the $C_{1}$-symmetric dimer $(\mathbf{1 2})_{2}{ }^{\mathrm{a}}$, already discussed in section 2.2. Next, the B-H-B and B-C-B bridges of $(\mathbf{1 2})_{2}{ }^{\mathrm{a}}$ are simultaneously cleaved along the dashed red line, and rotation about the central $\mathrm{C}-\mathrm{C}$ bond leads to a new isomer of dimeric 9-borafluorene (i.e. $(\mathbf{1 2})_{2}{ }^{\mathrm{c}}$ ), basically as a result of substituent scrambling. Given the facile insertion of ethylborane $\left(\left\{\mathrm{H}_{2} \mathrm{BEt}\right\}\right)$ into 9-ethyl-9-borafluorene (16; Scheme 6), it is plausible that the oligomerisation process continues through an attack of the $\mathrm{BH}_{2}$ head group of $(\mathbf{1 2})_{2}{ }^{\mathrm{c}}$ onto the central borole ring of a third monomer (a second viable pathway has also been identified computationally ${ }^{68}$ ). The trimer $(\mathbf{1 2})_{3}$ thus obtained, already possesses all key structural motifs of the pentamer $(\mathbf{1 2})_{5}$ : a 9-borafluorenyl tail group, a biphenylene linker and a 15-type head group. Ligand redistribution between the 9-borafluorenyl tail group of $(\mathbf{1 2})_{3}$ and a fourth monomer gives the tetramer $(\mathbf{1 2})_{4}$. In contrast to trimer $(\mathbf{1 2})_{3}$ (and all other related odd-numbered oligomers), one $\mathrm{B}-\mathrm{H}$ bond is present in tetramer $(\mathbf{1 2})_{4}$ (and in all other even-numbered oligomers) that cannot stabilise itself by intramolecular B-H-B bonding. (12) therefore readily picks up a fifth molecule of 9-borafluorene to form the experimentally observed pentamer $(\mathbf{1 2})_{5} .{ }^{68}$ The oligomerisation process stops at this stage, because $(\mathbf{1 2})_{5}$ crystallises from the hexane solution before it can grow further and not because thermodynamics pose a limit to chain propagation. ${ }^{68}$

The intrastrand $\mathrm{B}-\mathrm{H}-\mathrm{B}$ bridges in $(\mathbf{1 2})_{5}$ lead to boron tetracoordination and thereby interrupt the $\pi$-conjugation pathway along the oligomer backbone. Monodispersed fully delocalised systems should, however, be accessible by functionalisation of the boron centres through hydroboration reactions. With regard to the comparatively low molecular weight of these hypothetical species, we note that an effective conjugation length of only 4-5 repeating units has been calculated for related oligo( $p$-phenylenevinyleneborane)s. ${ }^{10}$

The major oligomerisation product $(\mathbf{1 2})_{5}$ has been isolated together with small amounts of the pentamers $\mathbf{3 3}$ and $\mathbf{3 4}$ (Scheme 10). Since the three species differ from each other only with regard to their chain ends, 33 likely forms from $(\mathbf{1 2})_{5}$ by extrusion of $\left\{\mathrm{BH}_{3}\right\}$, which subsequently inserts into the 9-borafluorenyl tail group of another molecule of $(\mathbf{1 2})_{5}$ to generate 34 (cf. the related reactivity of $\mathbf{1 6}$ and $\mathbf{1 7}$; Scheme 6). We also note that the compound 2,2'-bis(9-borafluorenyl)biphenyl, $\mathrm{H}_{8} \mathrm{C}_{12} \mathrm{~B}-$ 

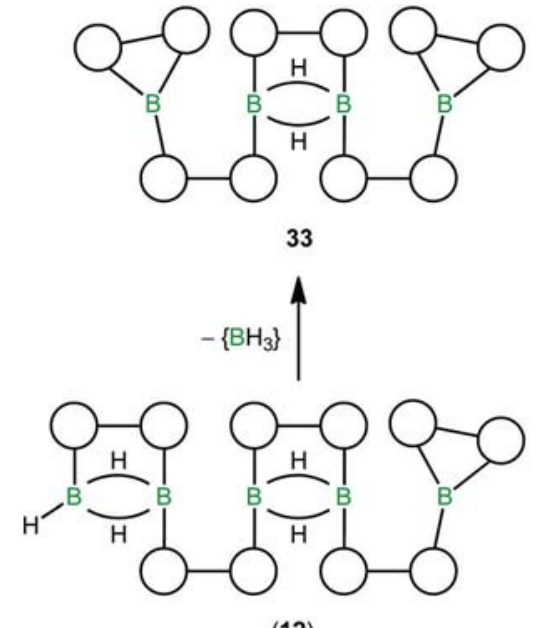

$(12)_{5}$
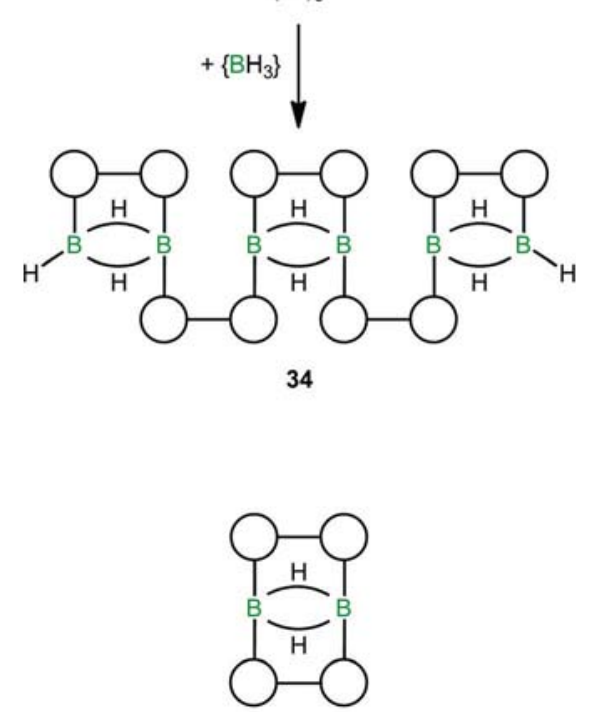

$(12)_{2}^{d}$

Scheme 10 Transformation of $(\mathbf{1 2})_{5}$ into $\mathbf{3 3}$ or $\mathbf{3 4}$ by $\left\{\mathrm{BH}_{3}\right\}$ extrusion or insertion; the highly symmetric cyclic dimer $(\mathbf{1 2})_{2}{ }^{\mathrm{d}}$ of 9 -borafluorene (12).

$\mathrm{C}_{6} \mathrm{H}_{4}-\mathrm{C}_{6} \mathrm{H}_{4}-\mathrm{BC}_{12} \mathrm{H}_{8}$, has already been described by Köster et $a l^{48,96}$ and Bettinger et $a l^{97}$ albeit in an entirely different context. 2,2'-Bis(9-borafluorenyl)biphenyl relates to the trimer $(\mathbf{1 2})_{3}$ (Scheme 9) in the same way as 33 relates to $(\mathbf{1 2})_{5}$.

If the reaction between 9-bromo-9-borafluorene (11) and $\mathrm{Et}_{3} \mathrm{SiH}$ is carried out at elevated temperatures (e.g., in refluxing toluene), entropy disfavours the generation of higher oligomers and the cyclic dimer 1,2:1,2-bis(2,2'-biphenylylene)diborane $(6)^{71}$ $\left((12)_{2}{ }^{\mathrm{d}}\right.$; Scheme 10) can be obtained instead. ${ }^{68}$ The central B-H-B moieties of $(\mathbf{1 2})_{2}{ }^{\mathrm{d}}$ are far less reactive than equivalent bonds in 1,2-(2,2'-biphenylylene)diborane(6) (15), not to mention open-chain compounds $\mathrm{R}_{2} \mathrm{~B}-(\mu-\mathrm{H})_{2}-\mathrm{BR}_{2}$. This finding provides compelling evidence that planar-constrained frameworks can indeed assist to achieve a greater inertness of organoboranes towards air and moisture ( $c f$. $\mathbf{C}$; Fig. 1). Another fact is also worth mentioning: to date, three different dimers of 9-borafluorene (i.e. $(\mathbf{1 2})_{2}{ }^{\mathrm{a}},(\mathbf{1 2})_{2}{ }^{\mathrm{c}}$ and $(\mathbf{1 2})_{2}{ }^{\mathrm{d}}$ ) have been described - but the most conventional isomer, $\mathrm{H}_{8} \mathrm{C}_{12} \mathrm{~B}-(\mu-\mathrm{H})_{2}-\mathrm{BC}_{12} \mathrm{H}_{8}\left((\mathbf{1 2})_{2}{ }^{\mathrm{b}}\right)$, still remains elusive.

\subsection{Condensation polymerisation of ferrocenyl(hydro)boranes}

Similar synthesis protocols to the ones leading from monotopic $\mathrm{FcBBr}_{2}(\mathbf{2 0}) / \mathrm{Li}\left[\mathrm{FcBH}_{3}\right]$ (22) to $\mathrm{Fc}_{2} \mathrm{BBr}(\mathbf{2 4}) / \mathrm{Fc}_{2} \mathrm{BH}$ (25) have been applied to transform the ditopic species $\mathrm{fc}\left(\mathrm{BBr}_{2}\right)_{2}(\mathbf{3 5})$ and $\mathrm{Li}_{2}\left[1,1^{\prime}-\mathrm{fc}\left(\mathrm{BH}_{3}\right)_{2}\right](\mathbf{3 6})$ into polymers $(-\mathrm{fc}-\mathrm{B}(\mathrm{Br})-)_{n}(37)^{77}$ and $(-\mathrm{fc}-\mathrm{B}(\mathrm{H})-)_{n}(38),{ }^{80}$ respectively $\left(\mathrm{fc}=1,1^{\prime}\right.$-ferrocenylene; Scheme 11) ${ }^{98}$ Analogous poly(ferrocenylene)s (-fc-ER - ER $_{x}$ with various bridging elements $\mathrm{E}$ are well known (e.g., $\mathrm{ER}_{x}=$ $\mathrm{SiMe}_{2}, \mathrm{GeMe}_{2}, \mathrm{PPh}$ ) and have tremendous potential for nanotechnology. ${ }^{99}$ Usually, these macromolecules are synthesised with high molecular weights via the ring-opening polymerisation (ROP) of strained, ring-tilted [1]ferrocenophanes. ${ }^{99}$ However, even though bora[1]ferrocenophanes do exist, ${ }^{100,101}$ their thermal ROP gave intractable materials together with small quantities of low molecular weight species. ${ }^{101}$ Thus, the condensation polymerisation reactions outlined in Scheme 11 currently provide the two major routes to soluble, well characterised boron-bridged poly(ferrocenylene)s.

So far, targeted aryl(hydro)borane redistribution reactions have mainly been conducted in the direction of decreasing steric hindrance, e.g., Trip ${ }_{2} \mathrm{BH}+\left\{\mathrm{BH}_{3}\right\} \rightarrow\left(\operatorname{TripBH}_{2}\right)_{2}{ }^{34,38}$ The synthesis of the poly(ferrocenylene)s $\mathbf{3 7}$ and $\mathbf{3 8}$ is therefore a rare example of a scrambling process leading to increased molecular complexity. Contrary to the ring-opening oligomerisation of 9borafluorene, which can be performed in a way to provide the cyclic dimer $(\mathbf{1 2})_{2}{ }^{\mathrm{d}}$ (Scheme 10), [1.1]diboraferrocenophanes (cyclo- $(-\mathrm{fc}-\mathrm{B}(\mathrm{R})-)_{2} ; \mathrm{R}=\mathrm{H}, \mathrm{Br}$ ) have not been identified as products of the condensation reactions. This is remarkable as the analogous [1.1]diborataferrocenophane $\left(\mathrm{Li}_{2}\right.$ [cyclo- $(-\mathrm{fc}-$ $\left.\left.\left.\mathrm{B}(\mathrm{Me})_{2}-\right)_{2}\right]\right),{ }^{102}$ as well as analogous Al-, Ga- and In-bridged cyclic dimers have been described. ${ }^{84,103,104}$

As outlined in Scheme 11, the primary polymers can cleanly be converted into soluble, more inert derivatives via hydroboration (cf. 39), ${ }^{80}$ nucleophilic substitution $(c f . \mathbf{4 0 , 4 1})^{77,105}$ or ether cleavage (cf. 42; Scheme 11). ${ }^{106}$ In the case of $\mathbf{4 0}$ (average $n=$ 24), the Mes substituent not only aids in the solubilisation of the material, but also provides steric protection to the tricoordinate boron bridges. Electrochemical measurements and UV/vis spectroscopy on $\mathbf{4 0}$ revealed pronounced electronic communication between individual iron atoms along the polymer backbone. ${ }^{77}$ The polycationic macromolecule 41 (average $n=17$ ) shows good stability under ambient conditions and is soluble in polar organic solvents. It is a highly redox-active material, both due to its ferrocenylene fragments $\left(\mathrm{Fe}^{\mathrm{II}} / \mathrm{Fe}^{\mathrm{III}}\right)$ and its 2,2'-bipyridylboronium sites, ${ }^{107,108}$ which, similar to the related compound Diquat, act as reversible two-electron acceptors. ${ }^{109-111}$ As to be expected, boron tetracoordination in $\mathbf{4 1}$ causes a smaller degree of electronic interactions between the ferrocenylene fragments than in $\mathbf{4 0}$ with tricoordinate boron bridges. However, pronounced charge transfer occurs from the electron-rich ferrocenylene units into the electron-poor bipyridylboronium groups, ${ }^{112}$ which results in an intense purple colour of $\mathbf{4 1}$ in solution. ${ }^{105}$ In the case of the alkoxy derivative $\mathbf{4 2}$, the degree of $\mathrm{Fe}-\mathrm{Fe}$ electronic interaction along the polymer chain is diminished compared to the mesityl derivative $\mathbf{4 0}$, because of the $\pi$-donor substituents present ( $c f$. the discussion of compounds $\mathbf{A}$; Fig. 1). ${ }^{106}$ It can therefore be concluded that the dangling substituent in boron-bridged poly(ferrocenylene)s provides an 

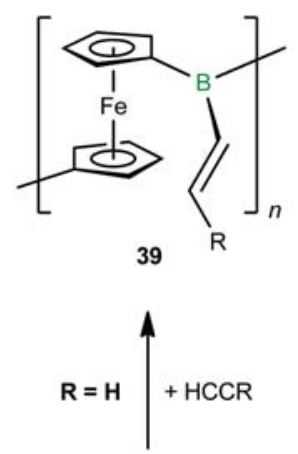

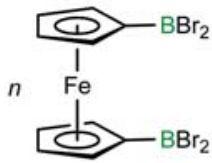

35

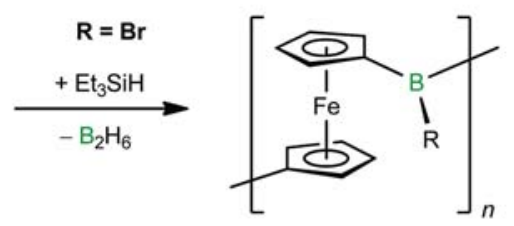

$37: \mathrm{R}=\mathrm{Br}$

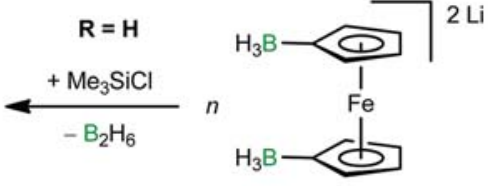

36

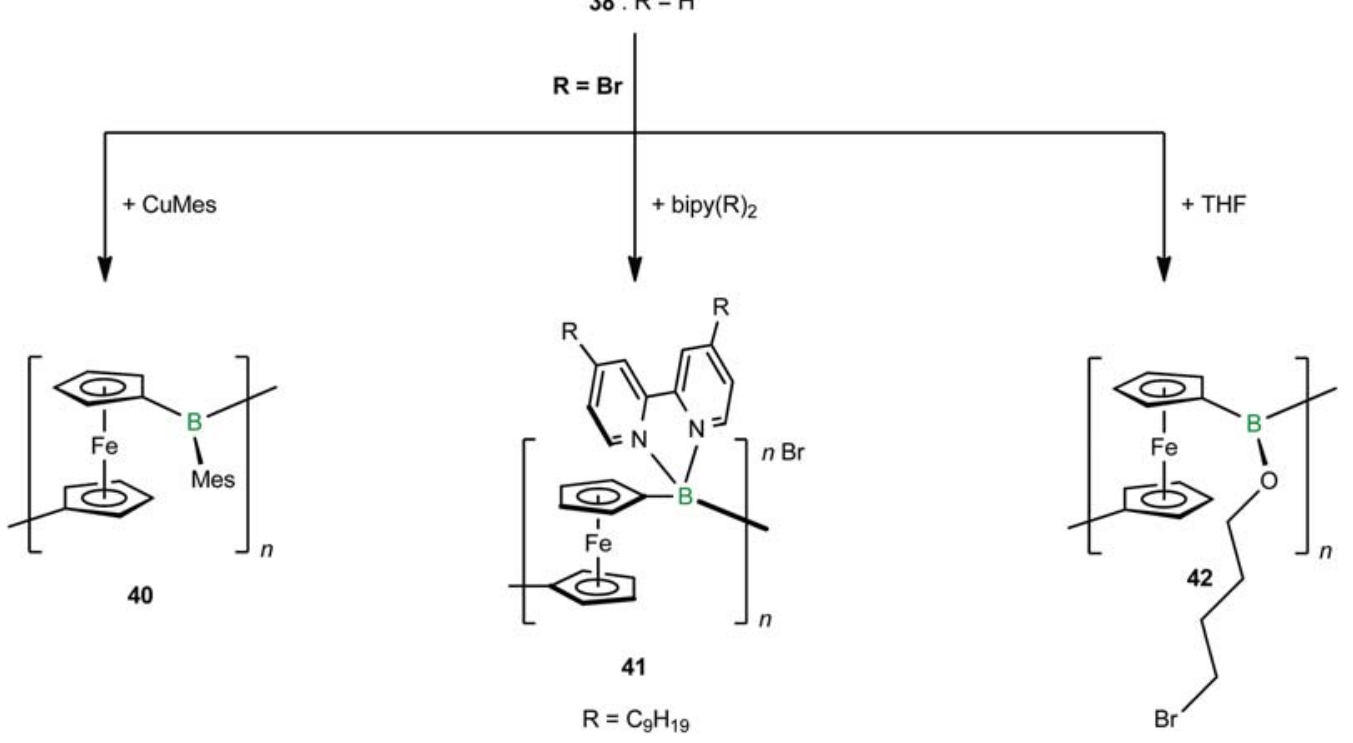

Scheme 11 Condensation polymerisation of $\mathbf{3 5}$ or $\mathbf{3 6}$ to give boron-bridged poly(ferrocenylene)s $\mathbf{3 7}$ or $\mathbf{3 8}$; different modes of derivatisation of $\mathbf{3 7}$ and 38. Note: the condensation reaction $\mathbf{3 5} \rightarrow \mathbf{3 7}$ yields $\left\{\mathrm{BH}_{2} \mathrm{Br}\right\}$ as the primary byproduct, which reacts further with excess $\mathrm{Et}_{3} \mathrm{SiH}$ to $\mathrm{B}_{2} \mathrm{H}_{6}$.

excellent set screw for adjusting the optoelectronic properties of these materials.

\section{Conclusions}

Aryl(hydro)boranes are valuable starting materials for the preparation of extended boron-doped $\pi$ systems, because they allow to exploit their unique properties in two ways: during the synthesis sequence, one takes advantage of their special reactivity, and later, the impact of the empty boron orbital modifies the electronic structures of the compounds obtained.

With regard to synthesis, the hydroboration of $\mathrm{C} \equiv \mathrm{C}$ triple bonds is currently among the best-established means of incorporating boron atoms into extended $\pi$-conjugated frameworks. On the other hand, targeted and controlled substituent scrambling, carried out as a condensation or ring-opening oligomerisation reaction, has recently also gained importance for the assembly of complex organoborane structures.

For an exchange of aryl groups between two triarylborane species, associated dimers connected by $\mathrm{B}-\mathrm{C}-\mathrm{B}$ three-centre, two-electron $(3 \mathrm{c}-2 \mathrm{e})$ bonds would be required. It has, however, been demonstrated, that triorganylboranes are strictly monomeric and not associated even in traces. Thus, the role of the hydrogen ligand in aryl(hydro)boranes is three-fold: (i) its small size poses minimal steric hindrance to dimerisation, (ii) the lack of $\pi$-donor capacity renders the boron atom highly Lewis acidic and (iii) the facile formation of one intermolecular $\mathrm{B}-\mathrm{H}-\mathrm{B} 3 \mathrm{c}-2 \mathrm{e}$ bond helps to set up an additional $\mathrm{B}-\mathrm{C}-\mathrm{B} 3 \mathrm{c}-2 \mathrm{e}$ bond (which is now pseudo-intramolecular; $c f$. (12) ${ }_{2}{ }^{\mathrm{a}}$ and the intermediate of ferrocenyl exchange in 23) and thereby supports substituent scrambling. In essence, dismutation reactions between aryl(hydro)boranes can be viewed as hydroboration events involving $\mathrm{B}-\mathrm{H}$ and $\mathrm{B}-\mathrm{C}$ single bonds. Even though this process has been regarded 
mainly as a nuisance in the past, we have shown with this perspective article that ongoing developments are turning substituent scrambling into a powerful tool for the construction of boron-containing macromolecules.

\section{Acknowledgements}

M.W. gratefully acknowledges financial support by the BeilsteinInstitut, Frankfurt/Main, Germany, within the research collaboration NanoBiC. A.L. and A.H. wish to thank the Fonds der Chemischen Industrie for Ph.D. grants.

\section{References}

1 H. Klauk, Organic Electronics: Materials, Manufacturing and Applications, Wiley-VCH, Weinheim, 2006.

2 F. So, Organic Electronics: Materials, Processing, Devices and Applications, CRC Press, Boca Raton, 2010.

3 M. M. Ling and Z. Bao, Chem. Mater., 2004, 16, 4824.

4 D. Braga and G. Horowitz, Adv. Mater., 2009, 21, 1473.

5 P. M. Beaujuge and J. M. J. Fréchet, J. Am. Chem. Soc., 2011, 133, 20009.

6 J. L. Delgado, P.-A. Bouit, S. Filippone, M. Á. Herranz and N. Martín, Chem. Commun., 2010, 46, 4853.

7 K. Müllen and U. Scherf, Organic Light Emitting Devices: Synthesis, Properties and Applications, Wiley-VCH, Weinheim, 2006.

8 Selected reviews: $(a)$ C. D. Entwistle and T. B. Marder, Angew. Chem., Int. Ed., 2002, 41, 2927; (b) C. D. Entwistle and T. B. Marder, Chem. Mater., 2004, 16, 4574; (c) S. Yamaguchi and A. Wakamiya, Pure Appl. Chem., 2006, 78, 1413; (d) N. Matsumi and Y. Chujo, Polym. J., 2008, 40, 77; (e) M. Elbing and G. C. Bazan, Angew. Chem., Int. Ed., 2008, 47, 834; ( $f$ ) F. Jäkle, Chem. Rev., 2010, 110, 3985.

9 Selected papers providing insight into the frontier-orbital structure of arylboranes on the basis of quantum-chemical calculations: (a) S. Yamaguchi, S. Akiyama and K. Tamao, J. Am. Chem. Soc., 2000, 122, 6335; (b) A. Sundararaman, K. Venkatasubbaiah, M. Victor, L. N. Zakharov, A. L. Rheingold and F. Jäkle, J. Am. Chem. Soc., 2006, 128, 16554; (c) T. W. Hudnall and F. P. Gabbaï, J. Am. Chem. Soc., 2007, 129, 11978 .

10 A. Nagai, T. Murakami, Y. Nagata, K. Kokado and Y. Chujo, Macromolecules, 2009, 42, 7217.

11 N. Sato, H. Ogawa, F. Matsumoto, Y. Chujo and T. Matsuyama, Synth. Met., 2005, 154, 113.

12 S. Luebben and S. Sapp, Mater. Matters, 2007, 2, 11.

13 M. Kinoshita, N. Fujii, T. Tsuzuki and Y. Shirota, Synth. Met., 2001, 121, 1571.

14 S. Cataldo, S. Fabiano, F. Ferrante, F. Previti, S. Patanè and B. Pignataro, Macromol. Rapid Commun., 2010, 31, 1281.

15 (a) Y.-L. Rao, H. Amarne, S.-B. Zhao, T. M. McCormick, S. Martić, Y. Sun, R.-Y. Wang and S. Wang, J. Am. Chem. Soc., 2008, 130, 12898; (b) C. Baik, Z. M. Hudson, H. Amarne and S. Wang, J. Am. Chem. Soc., 2009, 131, 14549; (c) S. K. Murphy, C. Baik, J. Lu and S. Wang, Org. Lett., 2010, 12, 5266; (d) C. Baik, S. K. Murphy and S. Wang, Angew. Chem., Int. Ed., 2010, 49, 8224; (e) H. Amarne, C. Baik, S. K. Murphy and S. Wang, Chem.-Eur. J., 2010, 16, 4750; $(f)$ H. Amarne, C. Baik, R.-Y. Wang and S. Wang, Organometallics, 2011, 30, 665 .

16 C. R. Wade, A. E. J. Broomsgrove, S. Aldridge and F. P. Gabbaï, Chem. Rev., 2010, 110, 3958.

17 Selected reviews: (a) K. Ishihara and H. Yamamoto, Eur. J. Org. Chem., 1999, 527; (b) E. Y.-X. Chen and T. J. Marks, Chem. Rev., 2000, 100, 1391; (c) D. W. Stephan, Dalton Trans., 2009, 3129; (d) D. W. Stephan and G. Erker, Angew. Chem., Int. Ed., 2010, 49, 46.

18 Selected references that have not been covered by the earlier reviews cited above: (a) A. Wakamiya, T. Taniguchi and S. Yamaguchi, Angew. Chem., Int. Ed., 2006, 45, 3170; (b) H. Li and F. Jäkle, Macromol. Rapid Commun., 2010, 31, 915; (c) H. Li, A. Sundararaman, T. Pakkirisamy, K. Venkatasubbaiah, F. Schödel and F. Jäkle, Macromolecules, 2011, 44, 95; (d) Z. M. Hudson, X.-Y. Liu and S. Wang, Org. Lett., 2011, 13, 300; (e) Z. M. Hudson, M. G. Helander, Z.-H. Lu and
S. Wang, Chem. Commun., 2011, 47, 755; ( $f$ ) C. Sun, J. Lu and S. Wang, Org. Lett., 2011, 13, 1226; ( $g$ ) E. Sakuda, Y. Ando, A. Ito and N. Kitamura, Inorg. Chem., 2011, 50, 1603; $(h)$ Y. Kim, H.-S. Huh, M. H. Lee, I. L. Lenov, H. Zhao and F. P. Gabbaï, Chem.-Eur. J., 2011, 17, 2057; (i) C. Bresner, C. J. E. Haynes, D. A. Addy, A. E. J. Broomsgrove, P. Fitzpatrick, D. Vidovic, A. L. Thompson, I. A. Fallis and S. Aldridge, New J. Chem., 2010, 34, 1652.

19 E. L. Muetterties, The Chemistry of Boron and its Compounds, John Wiley \& Sons, Inc., New York, London, Sydney, 1967.

20 C. Elschenbroich, Organometallics, Wiley-VCH, Weinheim, 2006.

21 Selected examples in which organolithium or Grignard reagents are used for the synthesis of (polymeric) organoboranes for optoelectronic applications: (a) N. Matsumi, K. Naka and Y. Chujo, J. Am. Chem. Soc., 1998, 120, 10776; (b) N. Matsumi, T. Umeyama and Y. Chujo, Polym. Bull., 2000, 44, 431; (c) Y. Shirota, M. Kinoshita, T. Noda, K. Okumoto and T. Ohara, J. Am. Chem. Soc., 2000, 122, 11021; (d) M. Kinoshita, H. Kita and Y. Shirota, Adv. Funct. Mater., 2002, 12, 780; (e) H. Doi, M. Kinoshita, K. Okumoto and Y. Shirota, Chem. Mater., 2003, 15, 1080.

22 (a) A. Sundararaman and F. Jäkle, J. Organomet. Chem., 2003, 681 , 134; (b) S. A. Cummings, M. Iimura, C. J. Harlan, R. J. Kwaan, I. V. Trieu, J. R. Norton, B. M. Bridgewater, F. Jäkle, A. Sundararaman and M. Tilset, Organometallics, 2006, 25, 1565. Jäkle et al. pioneered the use of $(\mathrm{MesCu})$ and $\left(\mathrm{C}_{6} \mathrm{~F}_{5}\right) \mathrm{Cu}$ for the post-polymerisation derivatisation of organoboron polymers: (c) Y. Qin, G. Cheng, A. Sundararaman and F. Jäkle, J. Am. Chem. Soc., 2002, 124, 12672; (d) K. Parab, K. Venkatasubbaiah and F. Jäkle, J. Am. Chem. Soc., 2006, 128, 12879; (e) H. Li, A. Sundararaman, K. Venkatasubbaiah and F. Jäkle, J. Am. Chem. Soc., 2007, 129, 5792; (f) H. Li and F. Jäkle, Angew. Chem., Int. $E d ., 2009,48,2313$; ( $g$ ) C. Cui, E. M. Bonder and F. Jäkle, J. Am. Chem. Soc., 2010, 132, 1810; $(h)$ P. Chen, R. A. Lalancette and F. Jäkle, J. Am. Chem. Soc., 2011, 133, 8802; (i) H. Li and F. Jäkle, Polym. Chem., 2011, 2, 897.

23 Representative examples particularly relevant in the context of this paper: (a) H. Gilman and L. O. Moore, J. Am. Chem. Soc., 1958, 80, 3609; $(b)$ W. Gerrard, M. Howarth, E. F. Mooney and D. E. Pratt, J. Chem. Soc., 1963, 1582; (c) F. E. Brinckman and F. G. A. Stone, J. Am. Chem. Soc., 1960, 82, 6218; (d) P. I. Paetzold and H. G. Smolka, Chem. Ber., 1970, 103, 289; (e) K. J. Alford, E. O. Bishop and J. D. Smith, J. Chem. Soc., Dalton Trans., 1976, 920.

24 Representative general examples particularly relevant in the context of this paper: (a) G. E. Herberich, B. Buller, B. Hessner and W. Oschmann, J. Organomet. Chem., 1980, 195, 253; (b) D. Kaufmann, Chem. Ber. 1987, 120, 901; (c) J. J. Eisch, J. E. Galle, B. Shafii and A. L. Rheingold, Organometallics, 1990, 9, 2342; (d) M. C. Haberecht, J. B. Heilmann, A. Haghiri, M. Bolte, J. W. Bats, H.-W. Lerner, M. C. Holthausen and M. Wagner, Z. Anorg. Allg. Chem., 2004, 630, 904; (e) A. Caruso, Jr. and J. D. Tovar, Org. Lett., 2011, 13, 3106; (f) cf. ref. $9 \mathrm{~b}$. Selected examples for the synthesis of organoboron polymers through $\mathrm{Si} / \mathrm{B}$ or $\mathrm{Sn} / \mathrm{B}$ exchange: $(g)$ A. Sundararaman, M. Victor, R. Varughese and F. Jäkle, J. Am. Chem. Soc., 2005, 127, 13748; (h) cf. ref. $22 c ;(i) c f$. ref. $22 e ;(j) c f$. ref. $22 f ;(k) c f$. ref. $22 h ;(l) c f$. ref. $22 i$.

25 (a) T. Renk, W. Ruf and W. Siebert, J. Organomet. Chem., 1976, 120, 1; (b) A. Appel, H. Nöth and M. Schmidt, Chem. Ber., 1995, 128, 621; (c) U. D. Eckensberger, K. Kunz, M. Bolte, H.-W. Lerner and M. Wagner, Organometallics, 2008, 27, 764.

26 Selected references: $(a)$ T. Ishiyama, M. Murata and N. Miyaura, J. Org. Chem., 1995, 60, 7508; (b) M. Murata, S. Watanabe and Y. Masuda, J. Org. Chem., 1997, 62, 6458; (c) M. Murata, T. Oyama, S. Watanabe and Y. Masuda, J. Org. Chem., 2000, 65, 164; (d) O. Baudoin, D. Guénard and F. Guéritte, J. Org. Chem., 2000, 65, 9268; (e) A. Fürstner and G. Seidel, Org. Lett., 2002, 4, 541; $(f)$ B. M. Rosen, C. Huang and V. Percec, Org. Lett., 2008, 10, 2597; (g) D. A. Wilson, C. J. Wilson, B. M. Rosen and V. Percec, Org. Lett., 2008, 10, 4879; $(h)$ C. Kleeberg, L. Dang, Z. Lin and T. B. Marder, Angew. Chem., Int. Ed., 2009, 48, 5350 .

27 Selected reviews: (a) T. Ishiyama and N. Miyaura, Chem. Rec., 2004, 3, 271; (b) I. A. I. Mkhalid, J. H. Barnard, T. B. Marder, J. M. Murphy and J. F. Hartwig, Chem. Rev., 2010, 110, 890.

28 N. Miyaura and A. Suzuki, Chem. Rev., 1995, 95, 2457.

29 D. Franz, M. Bolte, H.-W. Lerner and M. Wagner, Dalton Trans., 2011, 40, 2433.

30 D. Franz, A. Haghiri Ilkhechi, M. Bolte, H.-W. Lerner and M. Wagner, Eur. J. Inorg. Chem., 2011, 5414

31 Ö. Seven and M. Wagner, manuscript in preparation. 
32 Selected reviews: (a) T. B. Marder and N. C. Norman, Top. Catal., 1998, 5, 63; (b) T. Ishiyama and N. Miyaura, J. Organomet. Chem., 2000, 611, 392; (c) V. M. Dembitsky, H. Abu Ali and M. Srebnik, Appl. Organomet. Chem., 2003, 17, 327.

33 P. V. Ramachandran and H. C. Brown, Organoboranes for Syntheses (ACS Symposium Series 783), American Chemical Society, Washington, DC, 2001 .

34 K. Smith, A. Pelter and Z. Jin, Angew. Chem., Int. Ed. Engl., 1994, 33, 851 .

35 J. Hooz, S. Akiyama, F. J. Cedar, M. J. Bennett and R. M. Tuggle, J. Am. Chem. Soc., 1974, 96, 274

36 A. Pelter, S. Singaram and H. Brown, Tetrahedron Lett., 1983, 24, 1433.

37 R. A. Bartlett, H. V. R. Dias, M. M. Olmstead, P. P. Power and K. J. Weese, Organometallics, 1990, 9, 146.

38 A. Pelter, K. Smith, D. Buss and Z. Jin, Heteroat. Chem., 1992, 3, 275.

39 K. Smith, A. Pelter and Z. Jin, J. Chem. Soc., Perkin Trans. 1, 1993, 395

40 A. Pelter, K. Smith, D. Buss and A. Norbury, Tetrahedron Lett., 1991, 32, 6239 .

41 D. J. Parks, R. E. v. H. Spence and W. E. Piers, Angew. Chem., Int. Ed. Engl., 1995, 34, 809.

42 D. J. Parks, W. E. Piers and G. P. A. Yap, Organometallics, 1998, 17, 5492.

43 A. Schnurr, K. Samigullin, J. M. Breunig, M. Bolte, H.-W. Lerner and M. Wagner, Organometallics, 2011, 30, 2838

44 E. Negishi and H. C. Brown, Synthesis, 1974, 77.

45 B. M. Trost, Angew. Chem., Int. Ed. Engl., 1995, 34, 259.

46 R. Köster and G. Bruno, Liebigs Ann. Chem., 1960, 629, 89.

47 R. Köster and G. Schomburg, Angew. Chem., 1960, 72, 567.

48 R. Köster, Angew. Chem., Int. Ed. Engl., 1964, 3, 174.

49 (a) K. Venkatasubbaiah, L. N. Zakharov, W. S. Kassel, A. L. Rheingold and F. Jäkle, Angew. Chem., Int. Ed., 2005, 44, 5428; (b) K. Venkatasubbaiah, I. Nowik, R. H. Herber and F. Jäkle, Chem. Commun., 2007, 2154; (c) K. Venkatasubbaiah, T. Pakkirisamy, R. A. Lalancette and F. Jäkle, Dalton Trans., 2008, 4507; (d) T. Pakkirisamy, K. Venkatasubbaiah, W. S. Kassel, A. L. Rheingold and F. Jäkle, Organometallics, 2008, 27, 3056; (e) K. Venkatasubbaiah, A. Doshi, I. Nowik, R. H. Herber, A. L. Rheingold and F. Jäkle, Chem.Eur. J., 2008, 14, 444.

50 Selected original publications: (a) J. J. Eisch, N. K. Hota and S. Kozima, J. Am. Chem. Soc., 1969, 91, 4575; (b) P. v. Ragué Schleyer, P. K. Freeman, H. Jiao and B. Goldfuss, Angew. Chem., Int. Ed. Engl., 1995, 34, 337; (c) C.-W. So, D. Watanabe, A. Wakamiya and S. Yamaguchi, Organometallics, 2008, 27, 3496; (d) H. Braunschweig, I. Fernández, G. Frenking and T. Kupfer, Angew. Chem., Int. Ed., 2008, 47, 1951; (e) C. Fan, W. E. Piers and M. Parvez, Angew. Chem., Int. Ed., 2009, 48, 2955; $(f)$ C. Fan, L. G. Mercier, W. E. Piers, H. M. Tuononen and M. Parvez, J. Am. Chem. Soc., 2010, 132, 9604; (g) J. Köhler, S. Lindenmeier, I. Fischer, H. Braunschweig, T. Kupfer, D. Gamon and C.-W. Chiu, J. Raman Spectrosc., 2010, 41, 636; (h) H. Braunschweig, C.-W. Chiu, A. Damme, K. Ferkinghoff, K. Kraft, K. Radacki and J. Wahler, Organometallics, 2011, 30, 3210; (i) A. Iida and S. Yamaguchi, J. Am. Chem. Soc., 2011, 133, 6952. Selected reviews: $(j)$ A. T. Balaban, D. C. Oniciu and A. R. Katritzky, Chem. Rev., 2004, 104, 2777; (k) H. Braunschweig and T. Kupfer, Chem. Commun., 2011, 47, 10903

51 (a) A. J. Leusink, W. Drenth, J. G. Noltes and G. J. M. van der Kerk, Tetrahedron Lett., 1967, 8, 1263; (b) J. M. Schulman, R. L. Disch and M. L. Sabio, J. Am. Chem. Soc., 1982, 104, 3785; (c) J. M. Schulman, R. L. Disch and M. L. Sabio, J. Am. Chem. Soc., 1984, 106, 7696; (d) J. M. Schulman and R. L. Disch, Organometallics, 1989, 8, 733; (e) A. J. Ashe, W. Klein and R. Rousseau, Organometallics, 1993, 12, 3225; $(f)$ G. Subramanian, P. v. Ragué Schleyer and H. Jiao, Organometallics, 1997, 16, 2362; (g) J. M. Schulman and R. L. Disch, Organometallics, 2000, 19, 2932.

52 Selected theoretical papers: $(a)$ R. Carbó, M. S. de Giambiagi and M. Giambiagi, Theor. Chim. Acta, 1969, 14, 147; (b) S. T. Massey and R. W. Zoellner, Int. J. Quantum Chem., 1991, 39, 787; (c) M. Kranz and T. Clark, J. Org. Chem., 1992, 57, 5492. Liu et al. have reported a substantial degree of aromatic stabilisation in 1,2-dihydro-1,2-azaborines: (d) E. R. Abbey, L. N. Zakharov and S.-Y. Liu, J. Am. Chem. Soc., 2008, 130, 7250; (e) A. J. V. Marwitz, M. H. Matus, L. N. Zakharov, D. A. Dixon and S.-Y. Liu, Angew. Chem., Int. Ed., 2009, 48, 973; (f) P. G. Campbell, E. R. Abbey, D. Neiner, D. J. Grant, D. A. Dixon and S.-Y. Liu, J. Am. Chem. Soc., 2010, 132, 18048.
53 Selected references: (a) C. K. Narula and H. Nöth, J. Organomet. Chem., 1985, 281, 131; (b) C. K. Narula and H. Nöth, Inorg. Chem., 1985, 24, 2532; (c) U. Gross and D. Kaufmann, Chem. Ber, 1987, 120, 991; (d) W. J. Grigsby and P. P. Power, J. Am. Chem. Soc., 1996, 118, 7981; (e) P. A. Chase, W. E. Piers and B. O. Patrick, J. Am. Chem. Soc., 2000, 122, 12911; (f) R. J. Wehmschulte, M. A. Khan, B. Twamley and B. Schiemenz, Organometallics, 2001, 20, 844; (g) S. Yamaguchi, T. Shirasaka, S. Akiyama and K. Tamao, J. Am. Chem. Soc., 2002, 124, 8816; $(h)$ R. J. Wehmschulte, A. A. Diaz and M. A. Khan, Organometallics, 2003, 22, 83; (i) P. E. Romero, W. E. Piers, S. A. Decker, D. Chau, T. K. Woo and M. Parvez, Organometallics, 2003, 22, 1266; (j) J. D. Hoefelmeyer, S. Solé and F. P. Gabbaï, Dalton Trans., 2004, 1254; (k) S. Bontemps, G. Bouhadir, K. Miqueu and D. Bourissou, J. Am. Chem. Soc., 2006, 128, 12056; ( $l$ ) P. A. Chase, L. D. Henderson, W. E. Piers, M. Parvez, W. Clegg and M. R. J. Elsegood, Organometallics, 2006, 25, 349; ( $m$ ) A. Wakamiya, K. Mishima, K. Ekawa and S. Yamaguchi, Chem. Commun., 2008, 579; (n) S. P. Lewis, J. Chai, S. Collins, T. J. J. Sciarone, L. D. Henderson, C. Fan, M. Parvez and W. E. Piers, Organometallics, 2009, 28, 249; (o) Q. Zhao, H. Zhang, A. Wakamiya and S. Yamaguchi, Synthesis, 2009, 127.

54 Selected references: $\boldsymbol{X}=\boldsymbol{B R}$ : (a) R. Clément, C. R. Acad. Sci., Paris, 1965, 261, 4436; (b) W. Schacht and D. Kaufmann, J. Organomet. Chem., 1987, 331, 139; (c) J. J. Eisch and B. W. Kotowicz, Eur. J. Inorg. Chem., 1998, 761; (d) V. C. Williams, C. Dai, Z. Li, S. Collins, W. E. Piers, W. Clegg, M. R. J. Elsegood and T. B. Marder, Angew. Chem., Int. Ed., 1999, 38, 3695; (e) M. V. Metz, D. J. Schwartz, C. L. Stern, P. N. Nickias and T. J. Marks, Angew. Chem., Int. Ed., 2000, 39, 1312; ( $f$ ) M. V. Metz, D. J. Schwartz, C. L. Stern, T. J. Marks and P. N. Nickias, Organometallics, 2002, 21, 4159; (g) S. Bieller, F. Zhang, M. Bolte, J. W. Bats, H.-W. Lerner and M. Wagner, Organometallics, 2004, 23, 2107; (h) J. Chen, J. W. Kampf and A. J. Ashe III, Organometallics, 2008, 27, 3639. $\boldsymbol{X}=\boldsymbol{C R}_{2}^{\prime}$ : (i) P. Jutzi, J. Organomet. Chem., 1969, 19, P1; $(j)$ R. van Veen and F. Bickelhaupt, J. Organomet. Chem., 1970, 24, 589; (k) P. Jutzi, Chem. Ber., 1971, 104, 1455; (l) R. van Veen and F. Bickelhaupt, J. Organomet. Chem., 1974, 74, 393; $(m)$ P. Finocchiaro, A. Recca, F. A. Bottino, F. Bickelhaupt, R. van Veen, H. Schenk and J. D. Schagen, J. Am. Chem. Soc., 1980, 102, 5594; (n) T. K. Wood, W. E. Piers, B. A. Keay and M. Parvez, Angew. Chem., Int. Ed., 2009, 48, 4009; (o) T. K. Wood, W. E. Piers, B. A. Keay and M. Parvez, Chem.-Eur. J., 2010, 16, 12199. $\boldsymbol{X}=\boldsymbol{N R}^{\prime}, \boldsymbol{P R}^{\prime}$ : (p) P. M. Maitlis, J. Chem. Soc., 1961, 425; (q) M. Kranz, F. Hampel and T. Clark, J. Chem. Soc., Chem. Commun., 1992, 1247; (r) T. Agou, J. Kobayashi and T. Kawashima, Org. Lett., 2005, 7, 4373; (s) T. Agou, J. Kobayashi and T. Kawashima, Org. Lett., 2006, 8, 2241; $(t)$ T. Agou, J. Kobayashi and T. Kawashima, Chem. Commun., 2007, 3204; (u) M. H. Lee, T. Agou, J. Kobayashi, T. Kawashima and F. P. Gabbaï, Chem. Commun., 2007, 1133; (v) T. Agou, J. Kobayashi and T. Kawashima, Chem.-Eur. J., 2007, 13, 8051; (w) T. Agou, M. Sekine, J. Kobayashi and T. Kawashima, Chem. Commun., 2009, 1894; (x) T. Agou, T. Kojima, J. Kobayashi and T. Kawashima, Org. Lett., 2009, 11, 3534; (y) T. Agou, M. Sekine, J. Kobayashi and T. Kawashima, Chem.-Eur. J., 2009, 15, 5056. $\boldsymbol{X}=\boldsymbol{O}, \boldsymbol{S}, \boldsymbol{S} \boldsymbol{e}:(z)$ J. M. Davidson and C. M. French, J. Chem. Soc., 1960, 191; (aa) J. M. Davidson and C. M. French, J. Chem. Soc., 1962, 3364; (ab) R. A. Bowie and O. C. Musgrave, J. Chem. Soc. C, 1970, 485; (ac) S. Solé and F. P. Gabbaï, Chem. Commun., 2004, 1284; (ad) M. Melaïmi, S. Solé, C.-W. Chiu, H. Wang and F. P. Gabbaï, Inorg. Chem., 2006, 45, 8136; (ae) J. Kobayashi, K. Kato, T. Agou and T. Kawashima, Chem.-Asian J., 2009, 4, 42; (af) T. Matsumoto, C. R. Wade and F. P. Gabbaï, Organometallics, 2010, 29, 5490.

55 Selected references: (a) L. G. Mercier, W. E. Piers and M. Parvez, Angew. Chem., Int. Ed., 2009, 48, 6108; (b) A. Caruso, Jr., M. A. Siegler and J. D. Tovar, Angew. Chem., Int. Ed., 2010, 49, 4213; (c) L. G. Mercier, S. Furukawa, W. E. Piers, A. Wakamiya, S. Yamaguchi, M. Parvez, R. W. Harrington and W. Clegg, Organometallics, 2011, 30, 1719; (d) A. Caruso, Jr. and J. D. Tovar, J. Org. Chem., 2011, 76, 2227.

56 E. E. van Tamelen, G. Brieger and K. G. Untch, Tetrahedron Lett., $1960,1,14$. The synthesis of parent $1 H$-borepin has also been reported: A. J. Ashe III, J. W. Kampf, Y. Nakadaira and J. M. Pace, Angew. Chem., Int. Ed. Engl., 1992, 31, 1255.

57 R. Köster and G. Benedikt, Angew. Chem., 1963, 75, 419.

58 R. van Veen and F. Bickelhaupt, J. Organomet. Chem., 1973, 47, 33.

59 J. Knizek and H. Nöth, J. Organomet. Chem., 2000, 614-615, 168. 
60 A. Lorbach, M. Bolte, H. Li, H.-W. Lerner, M. C. Holthausen, F. Jäkle and M. Wagner, Angew. Chem., Int. Ed., 2009, 48, 4584.

61 A. Lorbach, C. Reus, M. Bolte, H.-W. Lerner and M. Wagner, $A d v$ Synth. Catal., 2010, 352, 3443

62 E. Januszewski, A. Lorbach, R. Grewal, M. Bolte, J. W. Bats, H.W. Lerner and M. Wagner, Chem.-Eur. J., 2011, 17, 12696.

63 A. Lorbach, M. Bolte, H.-W. Lerner and M. Wagner, Organometallics, 2010, 29, 5762 .

64 A. Lorbach, M. Bolte, H.-W. Lerner and M. Wagner, Chem. Commun., 2010, 46, 3592 .

65 S. N. Kessler and H. A. Wegner, Org. Lett., 2010, 12, 4062.

66 S. N. Kessler, M. Neuburger and H. A. Wegner, Eur. J. Org. Chem., 2011, 3238.

67 A. Hübner, H.-W. Lerner, M. Wagner and M. Bolte, Acta Crystallogr., Sect. E: Struct. Rep. Online, 2010, E66, o444.

68 A. Hübner, Z.-W. Qu, U. Englert, M. Bolte, H.-W. Lerner, M. C. Holthausen and M. Wagner, J. Am. Chem. Soc., 2011, 133, 4596.

69 M. Pilz, J. Allwohn, W. Massa and A. Berndt, Angew. Chem., Int. Ed. Engl., 1990, 29, 399.

70 A. Das, A. Hübner, M. Weber, M. Bolte, H.-W. Lerner and M. Wagner, Chem. Commun., 2011, 47, 11339.

71 R. Köster and H.-G. Willemsen, Liebigs Ann. Chem., 1974, 1843.

72 H. Hong and T. C. Chung, J. Organomet. Chem., 2004, 689, 58.

73 B. Wrackmeyer, P. Thoma, R. Kempe and G. Glatz, Collect. Czech. Chem. Commun., 2010, 75, 743.

74 (a) R. Köster, Angew. Chem., 1960, 72, 626; (b) H. G. Weiss, W J. Lehmann and I. Shapiro, J. Am. Chem. Soc., 1962, 84, 3840; (c) G. Zweifel, K. Nagase and H. C. Brown, J. Am. Chem. Soc., 1962, 84, 183; (d) D. E. Young and S. G. Shore, J. Am. Chem. Soc., 1969, 91, 3497; (e) E. Breuer and H. C. Brown, J. Am. Chem. Soc., 1969, 91, 4164; $(f)$ H. C. Brown, E. Negishi and P. L. Burke, J. Am. Chem. Soc., 1970, 92, 6649; (g) H. C. Brown and E. Negishi, Pure Appl. Chem., 1972, 29, 527; (h) D. J. Saturnino, M. Yamauchi, W. R. Clayton, R. W. Nelson and S. G. Shore, J. Am. Chem. Soc., 1975 , 97, 6063 .

75 The reaction of 2,2'-dilithiobiphenyl with excess $\mathrm{Me}_{3} \mathrm{SiCl}$ does not provide 2,2'-bis(trimethylsilyl)biphenyl (formally an analog of $\mathbf{1 5}$ in Scheme 6), but rather 9,9-dimethyl-9-silafluorene (the analog of 9-borafluorene (12)) and $\mathrm{Me}_{4} \mathrm{Si}$ (the analog of $\left\{\mathrm{BH}_{3}\right\}$ ): (a) P. F. Hudrlik, D. Dai and A. M. Hudrlik, J. Organomet. Chem., 2006, 691, 1257; (b) V. J. Lillo, C. Gómez and M. Yus, Tetrahedron Lett., 2009, 50, 2266. A similar reactivity has also been observed when $\mathrm{Me}_{3} \mathrm{SnCl}, \mathrm{Ph}_{3} \mathrm{SnCl}$ and $\mathrm{Ph}_{3} \mathrm{PbCl}$ were used instead of $\mathrm{Me}_{3} \mathrm{SiCl}(c)$ R. Gelius, Angew. Chem., 1960, 72, 322; (d) W. Neugebauer, A. J. Kos and P. v. Ragué Schleyer, J. Organomet. Chem., 1982, 228, 107.

76 M. Scheibitz, J. B. Heilmann, R. F. Winter, M. Bolte, J. W. Bats and M. Wagner, Dalton Trans., 2005, 159.

77 J. B. Heilmann, M. Scheibitz, Y. Qin, A. Sundararaman, F. Jäkle, T. Kretz, M. Bolte, H.-W. Lerner, M. C. Holthausen and M. Wagner, Angew. Chem., Int. Ed., 2006, 45, 920.

78 M. Scheibitz, J. W. Bats, M. Bolte, H.-W. Lerner and M. Wagner, Organometallics, 2004, 23, 940

79 M. Scheibitz, M. Bolte, J. W. Bats, H.-W. Lerner, I. Nowik, R. H. Herber, A. Krapp, M. Lein, M. C. Holthausen and M. Wagner, Chem.-Eur. J., 2005, 11, 584

80 M. Scheibitz, H. Li, J. Schnorr, A. Sánchez Perucha, M. Bolte, H.W. Lerner, F. Jäkle and M. Wagner, J. Am. Chem. Soc., 2009, 131, 16319.

81 A. Appel, F. Jäkle, T. Priermeier, R. Schmid and M. Wagner, Organometallics, 1996, 15, 1188

82 L. Kaufmann, H. Vitze, M. Bolte, H.-W. Lerner and M. Wagner, Organometallics, 2008, 27, 6215.

83 U. D. Eckensberger, M. Weber, J. Wildt, M. Bolte, H.-W. Lerner and M. Wagner, Organometallics, 2010, 29, 5301.

84 Related condensation reactions of ferrocenylgallanes have been reported: (a) P. Jutzi, N. Lenze, B. Neumann and H.-G. Stammler, Angew. Chem., Int. Ed., 2001, 40, 1424; (b) A. Althoff, P. Jutzi, N. Lenze, B. Neumann, A. Stammler and H.-G. Stammler, Organometallics, 2002, 21, 3018; (c) A. Althoff, P. Jutzi, N. Lenze, B. Neumann, A. Stammler and H.-G. Stammler, Organometallics, 2003, 22, 2766. For an interesting Ga-bridged poly(ferrocenylene) that has not been obtained through a condensation reaction, $c f$. B. Bagh, J. B. Gilroy, A. Staubitz and J. Müller, J. Am. Chem. Soc., 2010, 132, 1794.

85 A. Lorbach, Ph.D. Thesis, Goethe-Universität Frankfurt, 2011.
86 Z. Yuan, C. D. Entwistle, J. C. Collings, D. Albesa-Jové, A S. Batsanov, J. A. K. Howard, N. J. Taylor, H. M. Kaiser, D. E. Kaufmann, S.-Y. Poon, W.-Y. Wong, C. Jardin, S. Fathallah, A. Boucekkine, J.-F. Halet and T. B. Marder, Chem.-Eur. J., 2006, 12, 2758 .

87 (a) N. Matsumi, K. Naka and Y. Chujo, J. Am. Chem. Soc., 1998, 120, 5112; (b) R. J. P. Corriu, T. Deforth, W. E. Douglas, G. Guerrero and W. S. Siebert, Chem. Commun., 1998, 963; (c) N. Matsumi, M. Miyata and Y. Chujo, Macromolecules, 1999, 32, 4467; (d) Y. Chujo, Y. Sasaki, N. Kinomura and N. Matsumi, Polymer, 2000, 41, 5047; (e) N. Matsumi, Y. Chujo, O. Lavastre and P. H. Dixneuf, Organometallics, 2001, 20, 2425; (f) M. Miyata and Y. Chujo, Polym. J., 2002, 34, 967; (g) M. Miyata and Y. Chujo, Polym. Bull., 2003, 51, 9.

88 P. Müller, S. Huck, H. Köppel, H. Pritzkow and W. Siebert, Z. Naturforsch. B, 1995, 50, 1476.

89 T. Agou, M. Sekine and T. Kawashima, Tetrahedron Lett., 2010, 51, 5013.

90 P. Müller, B. Gangnus, H. Pritzkow, H. Schulz, M. Stephan and W. Siebert, J. Organomet. Chem., 1995, 487, 235.

91 P. Müller, H. Pritzkow and W. Siebert, J. Organomet. Chem., 1996, 524, 41

92 J. Chai, C. Wang, L. Jia, Y. Pang, M. Graham and S. Z. D. Cheng, Synth. Met., 2009, 159, 1443.

93 H. C. Brown, E. Negishi and P. L. Burke, J. Am. Chem. Soc., 1971, 93, 3400 .

94 H. C. Brown, E. Negishi and P. L. Burke, J. Am. Chem. Soc., 1972, 94, 3561 .

95 H. C. Brown and E. Negishi, Tetrahedron, 1977, 33, 2331.

96 R. Köster, G. Benedikt, W. Fenzl and K. Reinert, Liebigs Ann. Chem., 1967, 702, 197.

97 S. Biswas, I. M. Oppel and H. F. Bettinger, Inorg. Chem., 2010, 49, 4499.

98 M. Wagner, Angew. Chem., Int. Ed., 2006, 45, 5916.

99 Selected reviews: (a) I. Manners, Adv. Organomet. Chem., 1995, 37, 131; (b) I. Manners, Polyhedron, 1996, 15, 4311; (c) P. Nguyen, P. Gómez-Elipe and I. Manners, Chem. Rev., 1999, 99, 1515; (d) I. Manners, Chem. Commun., 1999, 857; (e) K. Kulbaba and I. Manners, Macromol. Rapid Commun., 2001, 22, 711; $(f)$ I. Manners, Science, 2001, 294, 1664; ( g) V. Bellas and M. Rehahn, Angew. Chem., Int. Ed., 2007, 46, 5082; (h) D. E. Herbert, U. F. J. Mayer and I. Manners, Angew. Chem., Int. Ed., 2007, 46, 5060.

100 H. Braunschweig, R. Dirk, M. Müller, P. Nguyen, R. Resendes, D. P. Gates and I. Manners, Angew. Chem., Int. Ed. Engl., 1997, 36, 2338.

101 A. Berenbaum, H. Braunschweig, R. Dirk, U. Englert, J. C. Green, F. Jäkle, A. J. Lough and I. Manners, J. Am. Chem. Soc., 2000, 122, 5765 .

102 M. Scheibitz, R. F. Winter, M. Bolte, H.-W. Lerner and M. Wagner, Angew. Chem., Int. Ed., 2003, 42, 924.

103 J. A. Schachner, G. A. Orlowski, J. W. Quail, H.-B. Kraatz and J. Müller, Inorg. Chem., 2006, 45, 454.

104 J. A. Schachner, C. L. Lund, I. J. Burgess, J. W. Quail, G. Schatte and J. Müller, Organometallics, 2008, 27, 4703.

105 C. Cui, J. Heilmann-Brohl, A. Sánchez Perucha, M. D. Thomson, H. G. Roskos, M. Wagner and F. Jäkle, Macromolecules, 2010, 43, 5256.

106 J. B. Heilmann, Y. Qin, F. Jäkle, H.-W. Lerner and M. Wagner, Inorg. Chim. Acta, 2006, 359, 4802.

107 K. Ma, M. Scheibitz, S. Scholz and M. Wagner, J. Organomet. Chem., 2002, 652, 11.

108 W. E. Piers, S. C. Bourke and K. D. Conroy, Angew. Chem., Int. Ed., 2005, 44, 5016.

109 S. Hünig and I. Wehner, Heterocycles, 1989, 28, 359.

110 C. Cui and F. Jäkle, Chem. Commun., 2009, 2744.

111 (a) F. Fabrizi de Biani, T. Gmeinwieser, E. Herdtweck, F. Jäkle, F. Laschi, M. Wagner and P. Zanello, Organometallics, 1997, 16, 4776; (b) L. Ding, K. Ma, F. Fabrizi de Biani, M. Bolte, P. Zanello and M. Wagner, Organometallics, 2001, 20, 1041; (c) L. Ding, K. Ma, M. Bolte, F. Fabrizi de Biani, P. Zanello and M. Wagner, J. Organomet. Chem., 2001, 637-639, 390; (d) L. Ding, K. Ma, G. Dürner, M. Bolte, F. Fabrizi de Biani, P. Zanello and M. Wagner, J. Chem. Soc., Dalton Trans., 2002, 1566; (e) K. Ma, F. Fabrizi de Biani, M. Bolte, P. Zanello and M. Wagner, Organometallics, 2002, 21, 3979; (f) $c f$. ref. 76 .

112 M. D. Thomson, M. Novosel, H. G. Roskos, T. Müller, M. Scheibitz, M. Wagner, F. Fabrizi de Biani and P. Zanello, J. Phys. Chem. A, 2004, 108, 3281 . 